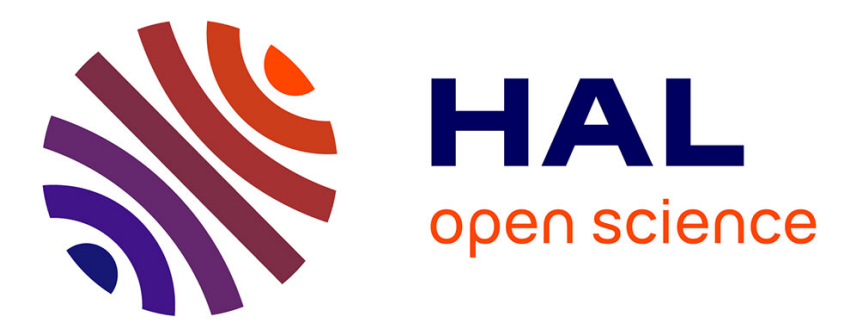

\title{
Benzothiadiazole Halogenation Impact in Conjugated Polymers, a Comprehensive Study
}

Théodore Olla, Olzhas Ibraikulov, Stéphanie Ferry, Olivier Boyron, Stéphane Méry, Benoît Heinrich, Thomas Heiser, Patrick Lévêque, Nicolas Leclerc

\section{- To cite this version:}

Théodore Olla, Olzhas Ibraikulov, Stéphanie Ferry, Olivier Boyron, Stéphane Méry, et al.. Benzothiadiazole Halogenation Impact in Conjugated Polymers, a Comprehensive Study. Macromolecules, 2019, 52 (21), pp.8006-8016. 10.1021/acs.macromol.9b01760 . hal-03000130

\section{HAL Id: hal-03000130 \\ https://hal.science/hal-03000130}

Submitted on 29 Nov 2020

HAL is a multi-disciplinary open access archive for the deposit and dissemination of scientific research documents, whether they are published or not. The documents may come from teaching and research institutions in France or abroad, or from public or private research centers.
L'archive ouverte pluridisciplinaire HAL, est destinée au dépôt et à la diffusion de documents scientifiques de niveau recherche, publiés ou non, émanant des établissements d'enseignement et de recherche français ou étrangers, des laboratoires publics ou privés. 


\section{Benzothiadiazole halogenation impact in conjugated polymers, a comprehensive study}

Théodore Olla, $\dagger$ Olzhas A. Ibraikulov, + Stéphanie Ferry, $\dagger$ Olivier Boyron, $\S$ Stéphane Méry, $\nabla$ Benoit Heinrich, $\nabla$ Thomas Heiser, $\neq$ Patrick Lévêque $\neq$ and Nicolas Leclerc $* \dagger$

$\dagger$ Institut de Chimie et Procédés pour l'Energie, l'Environnement et la Santé (ICPEES), Université de Strasbourg, CNRS, UMR 7515, 25 rue Becquerel, 67087 Strasbourg, Cedex 02, France. E-mail: leclercn@unistra.fr

‡ Laboratoire ICube, Université de Strasbourg, CNRS, UMR 7357, 23 rue du Loess, Strasbourg, 67037, France.

$\S$ Université de Lyon 1, CPE Lyon, CNRS UMR 5265, Laboratoire de Chimie Catalyse Polymères et Procédés (C2P2), Bat 308F, 43 bd du 11 Novembre 1918, 69616 Villeurbanne, France.

$\nabla$ Institut de Physique et Chimie des Matériaux de Strasbourg (IPCMS), Université de Strasbourg, CNRS, 23 rue du Loess, Strasbourg, 67034, France

Keywords: Halogenated Semiconducting Polymer; Polymer Backbone Engineering; Polymer Solar Cells; Structural Properties; Optoelectronic Properties. 


\begin{abstract}
The rise of halogenated organic semiconducting materials has led to a significant increase of organic photovoltaic power conversion efficiencies in recent years. However, the impact of halogen atoms on optoelectronic, structural and photovoltaic properties is not yet fully understood. In particular, because of different physico-chemical properties, the design of polymers using chlorine atoms instead of fluorine atoms still needs to be rationalized. In this paper, we investigate a series of 4 halogenated D-A electron donor copolymers, by varying not only the number of halogen atoms, but also their nature. The in-depth experimental and theoretical study of these new polymers, using the non-halogenated polymer as a reference, allowed us to rationalize the impact of these chemical modifications. In particular, we found that the structural properties and blending morphologies are mainly influenced by the nature of the halogen in this series of polymers. We have also demonstrated that a reasonable reduction in the number of fluorine atoms along the polymer backbone can be a good strategy to improve thin film processing conditions while keeping efficiencies at an acceptable level.
\end{abstract}

\title{
Introduction
}

Polymer solar cells (PSCs) have attracted particular attention in the last fifteen years due to promises of flexibility, light-weight, aesthetics features, semi-transparency and finally low costs. ${ }^{1}$ Bulk heterojunction (BHJ) PSCs, consisting in an active layer composed from a physical blend between an electron donor polymer and a fullerene-derivative electron acceptor or a nonfullerene acceptor (NFA) have been thoroughly studied. Therefore, thousands of semiconducting polymers have been investigated. Recently, a tremendous boost in power conversion efficiency 
(PCE) has been achieved, leading to record PCE of more than 15 to $16 \%$ in single layer devices. ${ }^{2,3}$ This efficiency improvement is mainly due to both, the rise of NFAs absorbing in the visible wavelength range and the halogenated polymers development. Indeed, since the pioneering work of $\mathrm{Yu}$ et al. in 2009 on the fluorination of the PTB series, it became clear that many benefits could be obtained when using partially fluorinated aromatic and heteroaromatic units along the polymer conjugated backbones. ${ }^{4}$ Actually, fluorine-substituted polymers usually exhibit i) deeper HOMO levels, leading to an increase in open-circuit voltages $\left(V_{o c}\right)$, ii) higher backbone planarity and iii) stronger $\pi$-stacking; the two latter being beneficial for charge-carrier transport. These particular features originate from the fluorine atom properties that include the highest electronegativity and a very small Van der Walls radius. The fluorine atom is thus hardly more sterically hindering than a hydrogen atom, while it can generate weak interactions with many elements, including chalcogens. However, the required aromatic fluorination is often tedious, leading to multistep and low-yield synthetic pathways. In addition, if the numerous fluorine weak interactions are advantageous for the charge transport properties, they turn to be detrimental for the final polymer solubility and most often require the use of a high temperature (around $100^{\circ} \mathrm{C}$ ) to be processed in solution. In view of these limitations, alternative methods should be considered in order to meet the industrial process constraints. Recently, polymer backbone substitution no longer by fluorine, but by chlorine atoms has appeared as a valuable synthetic alternative.

Indeed, chlorine atoms share several of the fluorine atomic properties, including a close electronegativity, although slightly lower. In addition, the aromatic electrophilic substitution by chlorine atoms is often easier and carried out from cheaper chemical reagents. Although much less studied than fluorinated ones, chlorinated organic semiconductor (OSC) materials have 
already shown promising properties and performances when used in optoelectronic devices. For instance, Tang et al., followed by Lei et al., have shown that chlorinated OSC generally exhibit even lower HOMO and LUMO energy levels than their fluorinated counterparts, leading to better electron transporting materials and/or more ambipolar OSCs. ${ }^{5,6}$ For these reasons, chlorinated polymers lead, most of the time, to higher $V_{o c}$ than their fluorinated counterparts when used in PSC active layers. ${ }^{7,8}$ Furthermore, Liu et al. mentioned that using chlorine atoms along a conjugated backbone decreases the polymer miscibility with the NFAs (ITIC in this case), thus increasing the size and purity of both donor and acceptor domains. ${ }^{9}$ All these features make chlorinated polymers interesting alternatives to fluorinated polymers. However, when dealing with chlorine substitution along the polymer conjugated backbone, the larger Van der Waals radius of the chlorine atom should be kept in mind, which is 1.33 times higher than the fluorine atom one and generates a much higher steric hindrance (almost twice the one of the fluorine). Consequently, chlorine substitution often induces torsion angles into the polymer conjugated backbones. ${ }^{10}$ This resulting twisted backbones is expected to improve the polymer solubility. However, the polymer backbone planarity must be sufficiently preserved to ensure the weak bonds network elaboration and the final solid state $\pi$-stacking.

We recently synthesized and characterized a difluorinated-benzothiadiazole based polymer, called $\mathbf{P F}_{2}$ (see Scheme 1), that showed high performances in PSCs with a PCE of $10.5 \%$ in blends with $\mathrm{PC}_{71} \mathrm{BM}$ on $12 \mathrm{~mm}^{2}$ area devices and even more than $6 \%$ on large area $\left(66 \mathrm{~cm}^{2}\right)$ ITO-free modules processed from non-chlorinated solvents. ${ }^{11,12}$ However and like most of the fluorinated polymers, the $\mathbf{P F}_{2}$ polymer suffers from a rather limited solubility in organic solvents and requires, consequently, a high processing temperature. Therefore, by synthesizing three new polymer derivatives (Scheme 1), we intend to investigate the impact of both the number and the 
nature of halogens substituted along the conjugated backbones on the polymer's optoelectronic properties and finally on the resulting PSC performances. In this study, by means of theoretical calculations and experimental characterizations, including X-ray diffraction tools, we demonstrate that a compromise between backbone torsion and solubility has to be found in order to obtain both satisfactory photovoltaic performances and processing conditions.

\section{Exeprimental part}

\section{Materials}

All reagents and chemicals were purchased from Aldrich and TCI. Toluene (ACS grade) was distilled from Na/benzophenone. The synthesis of the 5-chloro-2,1,3-benzothiadiazole, 5,6dichloro-2,1,3-benzothiadiazole, 5-fluoro-2,1,3-benzothiadiazole, 2-(trimethylstannyl)-4-(2octyldodecyl)thiophene, 2-(trimethylstannyl)-4-(dodecyl)thiophene, 2-(trimethylstannyl)-4-(2ethylhexyl)thiophene, 2-5-bis-trimethylstannyl-thieno[3,2-b]thiophene and 4,7-dibromo-5fluoro-2,1,3-benzothiadiazole have been prepared as described in the literature. ${ }^{11,13-16} \mathbf{P X}_{\mathbf{0}}$ and $\mathbf{P F}_{2}$ polymer synthesis have been already described previously. ${ }^{11}$

Synthesis of 4,7-dibromo-5-chloro-2,1,3-benzothiadiazole (4). In a schlenk, compound 5chloro-2,1,3-benzothiadiazole (1.7g, 1 eq.) and hydrobromic acid (48\% aq., $38 \mathrm{~mL}$ ) were introduced, under argon. Then, bromine ( $5 \mathrm{~mL}, 10$ eq.) in hydrobromic acid (48\% aq., $18 \mathrm{~mL})$ was added under argon, and the reaction mixture was stirred for 48 hours at $130 \mathrm{C}$. After cooling to room temperature, a solution of $\mathrm{Na}_{2} \mathrm{SO}_{3}(30 \mathrm{~g})$ in water $(100 \mathrm{~mL})$ was added, and the mixture was stirred for $30 \mathrm{~min}$, then chloroform extract, dried on anhydrous $\mathrm{Na}_{2} \mathrm{SO}_{4}$, filtered, concentrated and purified by flash chromatography (eluent: cyclohexane/dichloromethane, 4/1) to give the compound 4 with $22 \%$ yield. $\mathrm{NMR}{ }^{1} \mathrm{H}\left(400 \mathrm{MHz}, \mathrm{CDCl}_{3}\right) \delta(\mathrm{ppm})=7.95(1 \mathrm{H}, \mathrm{s})$. $\mathrm{NMR}{ }^{13} \mathrm{C}\left(100 \mathrm{MHz}, \mathrm{CDCl}_{3}\right) \delta(\mathrm{ppm})=153.4,151.6,137.0,133.6,114.0,113.7$. 
Synthesis of 4,7-dibromo-5,6-dichloro-2,1,3-benzothiadiazole (5). In a schlenk, compound 5,6-dichloro-2,1,3-benzothiadiazole (1g, 1 eq.) and hydrobromic acid (48\% aq., $16 \mathrm{~mL}$ ) were introduced, under argon. Then, bromine (5 mL, 20 eq.) in hydrobromic acid (48\% aq., $12 \mathrm{~mL}$ ) was added under argon, and the reaction mixture was stirred for 48 hours at $130 \mathrm{C}$. After cooling to room temperature, a solution of $\mathrm{Na}_{2} \mathrm{SO}_{3}(30 \mathrm{~g})$ in water $(100 \mathrm{~mL})$ was added, and the mixture was stirred for $30 \mathrm{~min}$, then chloroform extract, dried on anhydrous $\mathrm{Na}_{2} \mathrm{SO}_{4}$, filtered, concentrated and purified by recrystallization from chloroform to provide the compound $\mathbf{5}$ with $85 \%$ yield. $\mathrm{NMR}{ }^{13} \mathrm{C}\left(100 \mathrm{MHz}, \mathrm{CDCl}_{3}\right) \delta(\mathrm{ppm})=151.4,137.0,136.5,115.0$.

\section{General procedure for Stille cross-coupling.}

A flame dried Schlenck was charged with the dibromo-compound (1.0 equiv.) and the 2(trimethylstannyl)-4-(alkyl)thiophene compound (2 equiv. for chlorinated benzothiadiazole vs 4 equiv. for fluorinated benzothiadiazole). Anhydrous and degassed toluene (0.1M) was added under inert gas. Finally, the Pd-based catalyst system was added in one portion and the mixture was stirred 24 hours at $120^{\circ} \mathrm{C}$. After cooling to room temperature, the reaction mixture was filtered through a pad of celite and the toluene solution was evaporated under reduced pressure. Then, the crude material was purified by column chromatography.

Synthesis of 5-fluoro-4,7-bis(4-(2-octyldodecyl)-thiophen-2-yl)-2,1,3-benzothiadiazole (7). Catalyst system: $\mathrm{Pd}_{2}(\mathrm{dba})_{3}(2.0 \mathrm{~mol} \%)$ and $\mathrm{P}(o \text {-tolyl })_{3}(8.0 \mathrm{~mol} \%)$ in toluene. The crude product was purified by column chromatography (silica gel, petroleum ether). Yield: 99\%. ${ }^{1} \mathrm{H}$ NMR (400 $\left.\mathrm{MHz}, \mathrm{CDCl}_{3}\right) \delta(\mathrm{ppm})=8.07\left(1 \mathrm{H}, \mathrm{d}, \mathrm{J}^{4}=0.99 \mathrm{~Hz}\right) ; .95\left(1 \mathrm{H}, \mathrm{d}, \mathrm{J}^{4}=1.31 \mathrm{~Hz}\right) ; 7.74\left(1 \mathrm{H}, \mathrm{d}, \mathrm{J}^{4}=\right.$ $1.29 \mathrm{~Hz}) ; 7.12\left(1 \mathrm{H}, \mathrm{d}, \mathrm{J}^{4}=1.16 \mathrm{~Hz}\right) ; 7.06\left(1 \mathrm{H}, \mathrm{d}, \mathrm{J}^{4}=1.06 \mathrm{~Hz}\right) ; 2.64(4 \mathrm{H}, \mathrm{m}) ; 1.69(2 \mathrm{H}, \mathrm{m}) ; 1.25$ $(64 \mathrm{H}, \mathrm{m}) ; 0.87\left(6 \mathrm{H}, \mathrm{t}, \mathrm{J}^{3}=6.75 \mathrm{~Hz}\right)$. 
Synthesis of 5-chloro-4,7-bis(4-(2-octyldodecyl)-thiophen-2-yl)-2,1,3-benzothiadiazole (9). Catalyst system: $\mathrm{Pd}_{2}(\mathrm{dba})_{3}(2.0 \mathrm{~mol} \%)$ and $\mathrm{P}(o \text {-tolyl })_{3}(8.0 \mathrm{~mol} \%)$ in toluene. The crude product was purified by column chromatography (silica gel, cyclohexane). Yield: 90\%. ${ }^{1} \mathrm{H}$ NMR (400 $\left.\mathrm{MHz}, \mathrm{CDCl}_{3}\right) \delta(\mathrm{ppm})=7.95\left(1 \mathrm{H}, \mathrm{d}, \mathrm{J}^{4}=1.31 \mathrm{~Hz}\right) ; 7.92(1 \mathrm{H}, \mathrm{s}) ; 7.59\left(1 \mathrm{H}, \mathrm{d}, \mathrm{J}^{4}=1.37 \mathrm{~Hz}\right) ; 7.15$ $\left(1 \mathrm{H}, \mathrm{d}, \mathrm{J}^{4}=1.23 \mathrm{~Hz}\right) ; 7.06\left(1 \mathrm{H}, \mathrm{d}, \mathrm{J}^{4}=1.01 \mathrm{~Hz}\right) ; 2.64\left(4 \mathrm{H}, \mathrm{t}, \mathrm{J}^{4}=7.21 \mathrm{~Hz}\right) ; 1.68(2 \mathrm{H}, \mathrm{m}) ; 1.26$ (64H, m); 0.87 (6H, m).

Synthesis of 5,6-dichloro-4,7-bis(4-(2-octyldodecyl)-thiophen-2-yl)-2,1,3-benzothiadiazole (10). Catalyst system: $\mathrm{Pd}_{2}(\mathrm{dba})_{3}(2.0 \mathrm{~mol} \%)$ and $\mathrm{P}(o \text {-tolyl })_{3}(8.0 \mathrm{~mol} \%)$ in THF. The crude product was purified by column chromatography (silica gel, cyclohexane). Yield: 63\%. ${ }^{1} \mathrm{H}$ NMR $\left(400 \mathrm{MHz}, \mathrm{CDCl}_{3}\right) \delta(\mathrm{ppm})=7.47\left(2 \mathrm{H}, \mathrm{d},{ }^{4} \mathrm{~J}=1.39 \mathrm{~Hz}\right) ; 7.18\left(2 \mathrm{H}, \mathrm{d},{ }^{4} \mathrm{~J}=1.27 \mathrm{~Hz}\right) ; 2.65(4 \mathrm{H}, \mathrm{d}$, $\left.{ }^{3} \mathrm{~J}=6.68 \mathrm{~Hz}\right) ; 1.67(2 \mathrm{H}, \mathrm{m}) ; 1.25(64 \mathrm{H}, \mathrm{m}) ; 0.87\left(12 \mathrm{H}, \mathrm{t},{ }^{3} \mathrm{~J}=13.70 \mathrm{~Hz}\right) .{ }^{13} \mathrm{C}$ NMR $(100 \mathrm{MHz}$, $\left.\mathrm{CDCl}_{3}\right) \delta(\mathrm{ppm})=152.8,141.8,134.4,134.1,133.4,126.5,124.1,39.2,35.0,33.5,32.1,30.2$ $29.8,29.5,26.9,22.8,14.3$.

\section{General procedure for di-bromination.}

The initial conjugated compound, as obtained after Stille cross-coupling, (1.0 equiv.) was solubilized in DMF (0.05 M) under argon in the dark. NBS (2.0 equiv.) was added portion wise. The resulting solution was stirred at room temperature under argon overnight. Water and diethylether were added and the resulting solution was stirred for $2 \mathrm{~h}$. The organic phase was separated from the water phase and extracted with brine $(3 \times 100 \mathrm{~mL})$. The organic phase was dried with sodium sulfate, filtered and the solvent evaporated under reduced pressure. The crude product was purified by column chromatography.

Synthesis of 5-fluoro-4,7-bis(5-bromo-4-(2-octyldodecyl)-thiophen-2-yl)-2,1,3benzothiadiazole (12). The crude product was purified by flash column chromatography (silica 
gel, cyclohexane). Yield: 86\%. ${ }^{1} \mathrm{H}$ NMR $\left(400 \mathrm{MHz}, \mathrm{CDCl}_{3}\right) \delta(\mathrm{ppm})=7.93(1 \mathrm{H}, \mathrm{s}) ; 7.73(1 \mathrm{H}, \mathrm{s})$;

$7.93(1 \mathrm{H}, \mathrm{d}, \mathrm{J}=12.95 \mathrm{~Hz}) ; 2.58\left(4 \mathrm{H}, \mathrm{t}, \mathrm{J}^{3}=7.41 \mathrm{~Hz}\right) ; 1.76(2 \mathrm{H}, \mathrm{m}) ; 1.25(64 \mathrm{H}, \mathrm{m}) ; 0.86(6 \mathrm{H}, \mathrm{t}$, $\left.\mathrm{J}^{3}=6.84 \mathrm{~Hz}\right) .{ }^{13} \mathrm{C} \mathrm{NMR}\left(100 \mathrm{MHz}, \mathrm{CDCl}_{3}\right) \delta(\mathrm{ppm})=160.1,157.6,153.1,153.0,149.4,142.5$, $141.5,136.9,136.87,132.0,131.9,131.7,131.6,129.4,125.1,125.0,116.2,115.8,113.9,113.8$ $113.7,110.8,110.6,38.6,38.5,34.3,34.2,33.4,33.3,31.9,30.0,29.71,29.68,29.6,29.4,26.6$, 22.7, 14.1. $\mathrm{NMR}{ }^{19} \mathrm{~F}\left(400 \mathrm{MHz}, \mathrm{CDCl}_{3}\right) \delta(\mathrm{ppm})=-108.3$.

Synthesis of 5-chloro-4,7-bis(5-bromo-4-(2-octyldodecyl)-thiophen-2-yl)-2,1,3benzothiadiazole (14). The crude product was purified by flash column chromatography (silica gel, cyclohexane). Yield: 84\%. ${ }^{1} \mathrm{H}$ NMR $\left(400 \mathrm{MHz}, \mathrm{CDCl}_{3}\right) \delta(\mathrm{ppm})=7.84(1 \mathrm{H}, \mathrm{s}) ; 7.74(1 \mathrm{H}, \mathrm{s})$; $7.57(1 \mathrm{H}, \mathrm{s}) ; 2.58\left(4 \mathrm{H}, \mathrm{t}, \mathrm{J}^{3}=6.96 \mathrm{~Hz}\right) ; 1.74(2 \mathrm{H}, \mathrm{m}) ; 1.26(64 \mathrm{H}, \mathrm{m}) ; 0.87\left(6 \mathrm{H}, \mathrm{t}, \mathrm{J}^{3}=6.84 \mathrm{~Hz}\right)$. ${ }^{13} \mathrm{C} \mathrm{NMR}\left(100 \mathrm{MHz}, \mathrm{CDCl}_{3}\right) \delta(\mathrm{ppm})=154.6,150.9,142.6,141.2,136.8,134.0,133.6,133.1$, $129.7,127.4,125.8,123.3,113.8,113.6,38.7,34.4,34.4,33.5,32.1,30.2,29.8,29.5,26.7,22.8$, 14.3.

Synthesis of 5,6-dichloro-4,7-bis(5-bromo-4-(2-octyldodecyl)-thiophen-2-yl)-2,1,3benzothiadiazole (15). The crude product was purified by flash column chromatography (silica gel, cyclohexane). Yield: $71 \% .{ }^{1} \mathrm{H}$ NMR $\left(400 \mathrm{MHz}, \mathrm{CDCl}_{3}\right) \delta(\mathrm{ppm})=7.44(2 \mathrm{H}, \mathrm{s}) ; 2.60(4 \mathrm{H}, \mathrm{d}$, $\left.\mathrm{J}^{3}=7.09 \mathrm{~Hz}\right) ; 1.73(2 \mathrm{H}, \mathrm{m}) ; 1.25(64 \mathrm{H}, \mathrm{m}) ; 0.87\left(12 \mathrm{H}, \mathrm{t}, \mathrm{J}^{3}=13.3 \mathrm{~Hz}\right) .{ }^{13} \mathrm{C}$ NMR $(100 \mathrm{MHz}$ $\left.\mathrm{CDCl}_{3}\right) \delta(\mathrm{ppm})=152.4,141.3,134.2,133.9,133.5,125.6,113.9,38.7,33.3,33.6,32.1,30.2$, $29.8,29.5,26.8,22.8,14.3$.

\section{General Stille polymerization procedure.}

A flame dried Schlenck was charged with dibrominated compound (1.0 equiv) and the 2-5-bistrimethylstannyl-thieno[3,2-b]thiophene (1.0 equiv.). Anhydrous and degassed toluene (0.0125 M) was added under inert gas. Then, the $\mathrm{Pd}_{2}(\mathrm{dba})_{3}(2 \mathrm{~mol} \%)$ and $\mathrm{P}(\mathrm{o} \text {-tolyl })_{3}(8 \mathrm{~mol} \%)$ were 
added in one portion and the mixture was stirred 24 hours at $120^{\circ} \mathrm{C}$. The reaction was quenched with 2-(trimethylstannyl)-thiophene (0.6 equiv.) during 1 hour followed by 2-bromothiophene (0.6 equiv). Then, the polymer crude was purified by precipitation in methanol, filtered and separated by Soxhlet extraction with methanol, acetone, cyclohexane and chlorobenzene. Then, the sodium diethyldithiocarbamate solution was added in the chlorobenzene fraction and the mixture was stirred at $60^{\circ} \mathrm{C}$ during 1 hour. The organic phase was washed with water, separated and evaporated under reduced pressure. Finally, the polymer was precipitated in methanol, filtered and dried under reduced pressure at $40^{\circ} \mathrm{C}$ overnight, providing powder with a metallic shine. ${ }^{1} \mathrm{H}$ NMR spectra of polymers could be found in the supporting information (see Figures S1-S5). However, $\mathrm{PX}_{0}, \mathrm{PF}_{1}$ and $\mathrm{PF}_{2}$ are not soluble enough to give exploitable spectra.

\section{Results and Discussion}

\section{Polymer Synthesis}

The chemical structure of the copolymers is shown in Scheme 1. The synthesis of $\mathbf{P} \mathbf{X}_{\mathbf{0}}$ and $\mathbf{P F} \mathbf{F}_{\mathbf{2}}$ has already been described. ${ }^{11}$ Copolymers $\mathbf{P F}, \mathbf{P C l}_{\mathbf{1}}$ and $\mathbf{P C l}_{\mathbf{2}}$ were prepared following a synthetic route similar as for $\mathbf{P F}_{2}$. However, the procedure differs, not only from the halogenated benzothiadiazole unit to be synthesized, but also from the solvent used in the Stille crosscoupling step between the 4,7-Dibromo-5-chloro-2,1,3-benzothiadiazole (compound 4) or the 4,7-Dibromo-5,6-dichloro-2,1,3-benzothiadiazole (compound 5) units and the 2-trimethyltin-4octyldodecyl thiophene moieties (see Scheme 1). Indeed, once benzothiadiazole is chlorinated in 5 and/or 6 positions, the chlorine atoms become sensitive to the Stille coupling conditions, and they participate to the formation of tris-adduct byproducts. A short Stille cross-coupling scope between the chlorinated compound 5 and the tin-thiophene derivative allowed us to find suitable 
conditions to decrease the amount of byproducts and to increase the yield of trimers 10 (see Table 1).
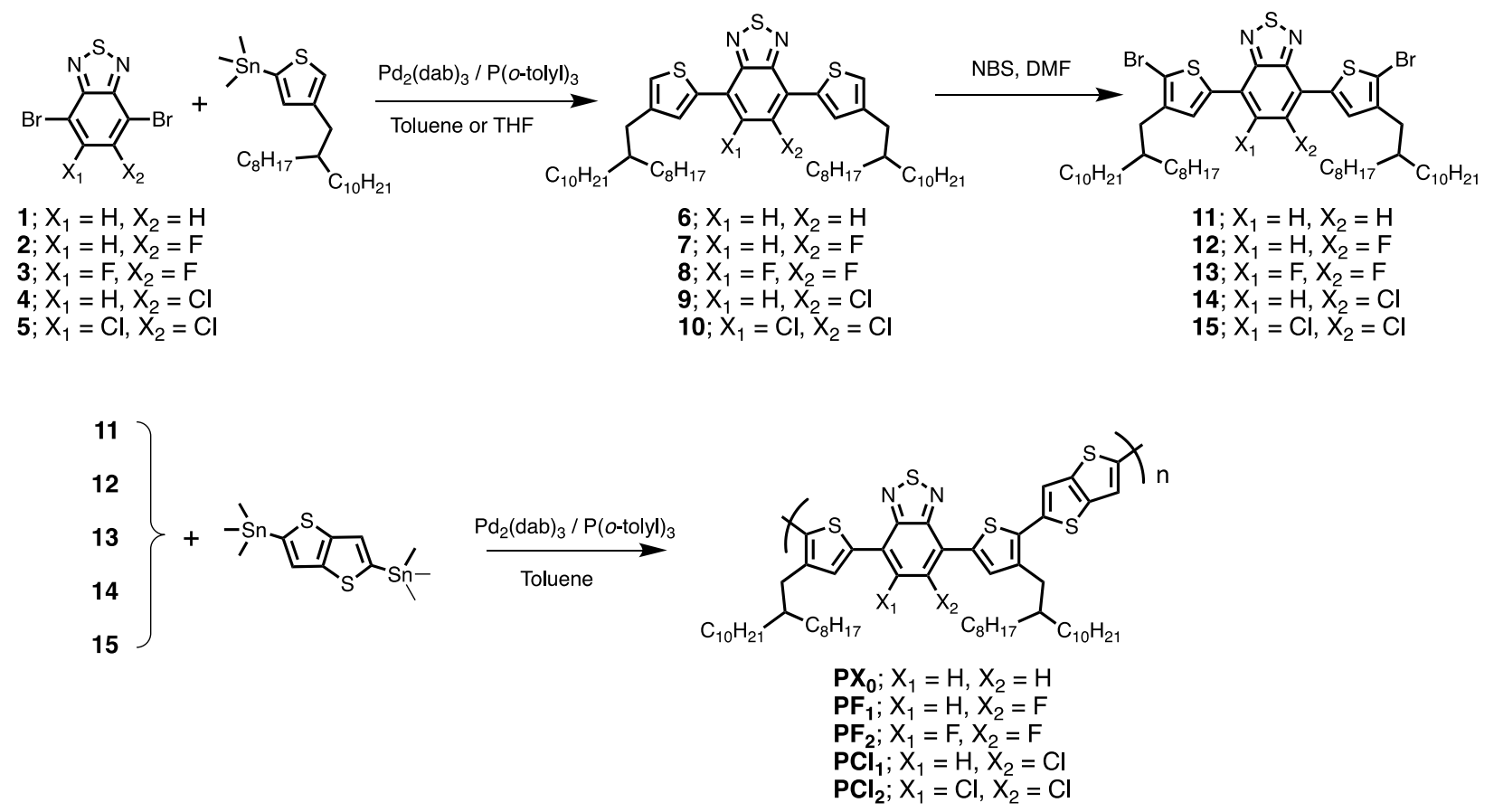

Scheme 1. Synthetic routes to the polymers

By varying the Pd-catalyst system, the nature of the solvent, the reaction time and the reaction temperature, we could optimize the conditions and select the best parameters as follow: the reaction is run in tetrahydrofuran $(\mathrm{THF})$ at $80^{\circ} \mathrm{C}$ for $4 \mathrm{~h}$, using $\mathrm{Pd}(\mathrm{dba})_{3}$ as $\mathrm{Pd}$ source and $\mathrm{P}(o-$ tol $)_{3}$ as ligand (Entry 5, Table 1). Of course, the stoichiometry has to be also taken into consideration when using the chlorinated benzothiadiazole species. In fact, a perfect stoichiometry of 1 to 2 between compound 5 and the trimethyltin-thiophene derivative is required to push further the reaction yield while keeping the tris-adduct byproduct formation moderate. 
Table 1. Optimization of Pd-Catalyzed bis-chlorinated benzothiadiazole condensation on the 2trimethyltin thiophene unit (synthesis of compound 10)

$\begin{array}{cccccc}\text { Entry } & \text { Catalyst } & \text { Solvent } & \begin{array}{c}\text { Time } \\ (\mathrm{h})\end{array} & \begin{array}{c}\text { Temp } \\ \left({ }^{\circ} \mathrm{c}\right)\end{array} & \begin{array}{c}\text { Compound 5 } \\ \text { isolated yield }(\%)\end{array} \\ 1 & \mathrm{Pd}\left(\mathrm{PPh}_{3}\right)_{4} & \text { THF } & 48 & 80 & 17 \\ 2 & \mathrm{Pd}\left(\mathrm{PPh}_{3}\right)_{4} & \text { Toluene } & 48 & 120 & 24 \\ 3 & \mathrm{Pd}(\mathrm{dppf}) \mathrm{Cl}_{2} & \text { THF } & 2 & 80 & 2 \\ 4 & \mathrm{Pd}(\mathrm{dppf}) \mathrm{Cl}_{2} & \text { Toluene } & 24 & 120 & 53 \\ 5 & \mathrm{Pd}(\mathrm{dba})_{3} / \mathrm{P}(o-\text {-tol })_{3} & \text { THF } & 4 & 80 & 63\end{array}$

Applied to the mono-chlorinated benzothiadiazole unit (compound 4), similar conditions led to the synthesis of compound 9 in $90 \%$ isolated yield, while for fluorinated derivatives, almost quantitative yields were obtained. Actually, in the case of fluorinated-benzothiadiazole units, since the fluorine atom is not reactive in the Stille conditions, the completion of the reaction can be further enhanced by increasing the initial feed ratio of the thiophene reagent as well as the reaction time.

The second step consists of the dibromination of the previous benzothiadiazole-based trimers in order to obtain the final reactive monomers. This reaction is based on a standard bromination using stoichiometric amounts of NBS in Dimethylformamide (DMF) or in a $\mathrm{DMF} / \mathrm{CHCl}_{3}$ mixture. All monomers were obtained in high yields ranging from $76 \%$ to $86 \%$.

Finally, the dibrominated monomers were all combined, by Stille cross-coupling polymerization, with the 2,5-bis(trimethyltin)thieno[3,2-b]thiophene to afford the corresponding halogenated polymers. Polymerization conditions were all identical, using the $\mathrm{Pd}_{2}(\mathrm{dba})_{3} / \mathrm{P}(o \text {-tol })_{3}$ catalyst system in toluene at $120^{\circ} \mathrm{C}$ for $24 \mathrm{~h}$. The polymers were purified by Soxhlet extraction from which the chlorobenzene (CB) fraction was collected and isolated for all polymers. The average molecular weights per number $(\mathrm{Mn})$, per weight $(\mathrm{Mw})$, and dispersity $(\bigoplus)$ of the synthesized polymers, were measured by high temperature size exclusion chromatography (SEC) at $150^{\circ} \mathrm{C}$ 
using 1,2,4-trichlorobenzene (TCB) as eluent and calibrated with narrow polystyrene standards. The characteristics of the polymers are summarized in Table 2. SEC profiles show monomodal distributions with no trace of residual monomers. It is to be noted that all polymers show $\mathrm{Mn}$ in similar range, while $Ð$ increases significantly for chlorinated polymers.

Table 2. Molecular weight and decomposition temperature of the polymers.

$\begin{array}{ccccc}\text { Polymer } & \begin{array}{c}{[\mathrm{Mn}]} \\ \left(\mathrm{kg} \cdot \mathrm{mol}^{-1}\right)\end{array} & \begin{array}{c}{[\mathrm{Mw}]} \\ \left(\mathrm{kg} \cdot \mathrm{mol}^{-1}\right)\end{array} & Ð & \begin{array}{c}\mathrm{T}_{\mathrm{d}}{ }^{a} \\ \left({ }^{\circ} \mathrm{C}\right)\end{array} \\ \mathbf{P X}_{\mathbf{0}} & 44.0 & 62.0 & 1.4 & 378 \\ \mathbf{P F}_{\mathbf{1}} & 34.4 & 100.0 & 2.9 & 390 \\ \mathbf{P F}_{\mathbf{2}} & 45.0 & 103.5 & 2.3 & 388 \\ \mathbf{P C l}_{\mathbf{1}} & 47.2 & 185.7 & 3.9 & 396 \\ \text { PCl }_{\mathbf{2}} & 50.0 & 202.0 & 3.9 & 400\end{array}$

a. Td: 5 percent weight loss temperatures measured by TGA at $5^{\circ} \mathrm{C} /$ min under $\mathrm{N}_{2}$ atmosphere.

All polymers were also characterized by TGA. All of them exhibit high thermal stability. Specifically, the thermograms in air and at $5^{\circ} \mathrm{C} / \mathrm{min}$ displayed no significant weight loss below ca. $250^{\circ} \mathrm{C}$ and $5 \%$ weight loss temperatures $\left(\mathrm{T}_{\mathrm{d}}\right)$ close to $300^{\circ} \mathrm{C}$. Nitrogen atmosphere even further delayed $\mathrm{T}_{\mathrm{d}}$ at values approaching $400^{\circ} \mathrm{C}$ (see Table 2 and Figures $\mathrm{S} 6$ and $\mathrm{S} 7 \mathrm{in} \mathrm{ESI}$ ).

\section{Structural properties of bulk polymers}

The five polymers are soft and slightly birefringent solids, until they flow at high temperature to turn into a viscous isotropic liquid state. The reverse transition, measured by DSC, is observed with a small delay on cooling $\left(0-15^{\circ} \mathrm{C}\right.$, except for $\left.\mathbf{P C l}_{\mathbf{1}}\right)$ (see Figure 1 left), which suggests that the structures are mesomorphic and could further explain the relatively low transition enthalpies (e.g. compared to $43 \mathrm{~J} / \mathrm{g}$ for crystallized infinite chains of $\mathrm{P} \mathrm{HT}^{17}$ ). Moreover, melting temperature and enthalpy are considerably increased for the fluorinated polymers, in consistency 
with the more cohesive self-assembly expected for them (see Table 3). In contrast, the effect of chlorination is found to be substantially less pronounced for $\mathbf{P C l}_{\mathbf{1}}$ and even deleterious for $\mathbf{P C l}_{\mathbf{2}}$.
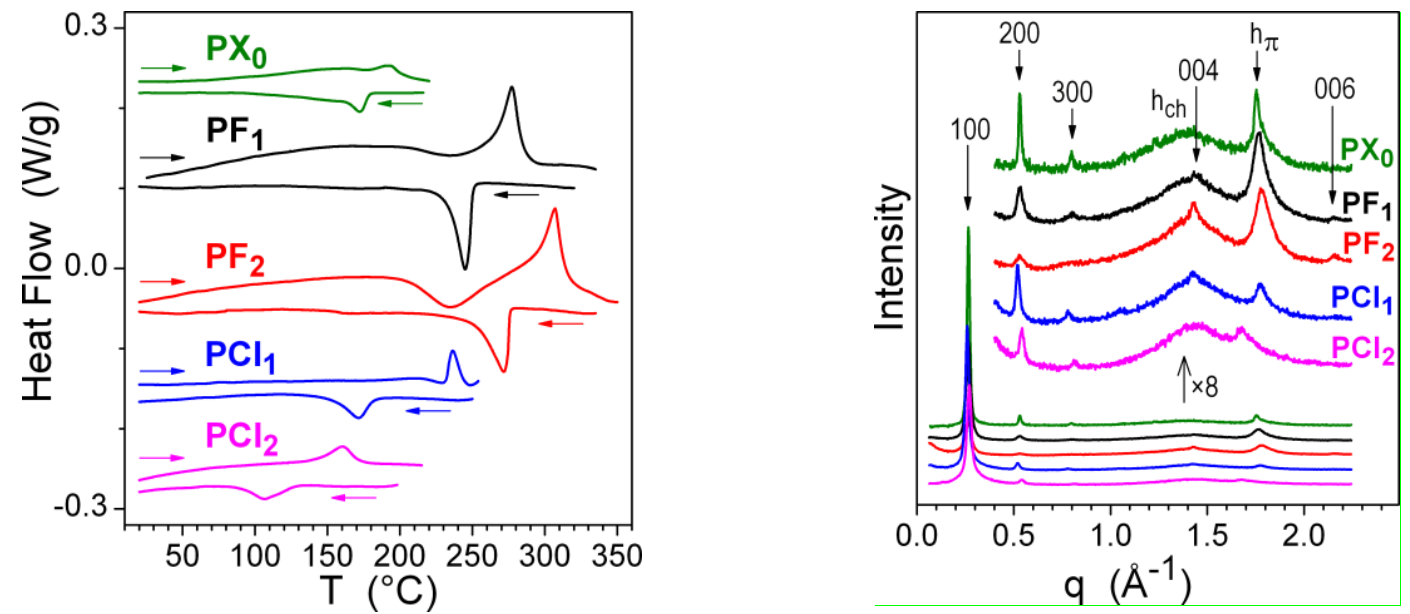

Figure 1. (Left) DSC curves of bulk polymers (DSC Q1000 from TA Instruments; conditions: $5^{\circ} \mathrm{C} \cdot \mathrm{min}^{-1}$, nitrogen atmosphere, endotherm up), displaying the transition to isotropic liquid state on heating and the reverse transition on cooling. (Right). SWAXS patterns of bulk polymers at $20^{\circ} \mathrm{C}$ and expansions of the mid- and wide-angle ranges, displaying the reflections series (h00) of a lamellar periodicity, the broad scattering signal from molten chains $\mathrm{h}_{\mathrm{ch}}$, the signal from $\pi$ stacking of backbones $h_{\pi}$ and, for $\mathbf{P F}_{2}$ and $\mathbf{P F}_{1}$, reflections (001) from periodicity along backbones.

The polymer self-assemblies were further investigated with Small- and Wide-Angle X-ray Scattering (SWAXS) (see Figure 1 right). The presence together of several sharp lamellar orders (h00), of a broad scattering signal from lateral distance between molten chains $h_{\mathrm{ch}}$, and of the scattering signal from $\pi$-stacking of backbones $h_{\pi}$ reveal the presence of lamellar structures with alternated backbone and molten chain layers, i.e. frozen lamellar mesophases (Lam). These materials are therefore structurally and thermodynamically equivalent to liquid-crystalline polymers, except that they are solid at room temperature and only slightly soften to tough pastes 
at higher temperature. Due to this absence of fluidity, the more general terminology "mesomorphic" is preferable to "liquid-crystalline". $\mathbf{P} \mathbf{X}_{\mathbf{0}}, \mathbf{P C l}_{\mathbf{1}}$ and $\mathbf{P} \mathbf{C l}_{\mathbf{2}}$ present no sharp signal other than the lamellar orders and thus form lamellar mesophases without long-range in-plane order. On the contrary and in line with previous results on $\mathbf{P F}_{2},{ }^{11}$ broadened reflections $(00 l)$ from periodicity along backbones are also visible in the patterns of $\mathbf{P F}_{\mathbf{1}}$ and $\mathbf{P} \mathbf{F}_{\mathbf{2}}$. The fluorinated backbones therefore stack with defined longitudinal shifts, indicating that they are locked in position by intermolecular interactions. However, none of the polymers gives rise to crossed reflections and thus, there is no defined positioning of successive backbone layers on top of each other into a three-dimensional structure. These structural features are the same at higher temperature, below the transition to isotropic liquid (see Figure S8 in ESI). Beyond this transition that could be crossed for $\mathbf{P X} \mathbf{X}_{\mathbf{0}}$ and $\mathbf{P} \mathbf{C l}_{\mathbf{2}}$, any long-range order is naturally lost, but a similar organization into layers is preserved at local-range, between neighboring polymers.

Table 3. Phase transition data and self-assembly parameters at $20^{\circ} \mathrm{C}$ for bulk polymers.

\begin{tabular}{|c|c|c|c|c|c|c|c|c|c|}
\hline & $\begin{array}{c}T_{\text {onset }}\left(T_{\max }\right)^{a}\left({ }^{\circ} \mathrm{C}\right) \\
\Delta \mathrm{H}[\mathrm{kJ} / \mathrm{mol}](\mathrm{J} / \mathrm{g})\end{array}$ & $\begin{array}{l}V_{\mathrm{ru}} \\
\left(\AA^{3}\right)\end{array}$ & $\begin{array}{c}\rho^{b} \\
\left(\mathrm{~g} / \mathrm{cm}^{3}\right)\end{array}$ & $\begin{array}{c}d_{\operatorname{lam}}{ }^{c} \\
(\AA)\end{array}$ & $\begin{array}{l}A_{\mathrm{ru}}{ }^{d} \\
\left(\AA^{2}\right)\end{array}$ & $\begin{array}{l}h_{\mathrm{ru}}^{e} \\
(\AA)\end{array}$ & $q_{\mathrm{ch}}^{f}$ & $\begin{array}{l}h_{\pi}^{g} \\
(\AA)\end{array}$ & $I\left(\mathrm{~h}_{\pi}\right) / I(001)$ \\
\hline $\mathbf{P X}_{\mathbf{0}}$ & $\begin{array}{c}178(194) \\
2.1(2.1)\end{array}$ & 1480 & 1.12 & 23.66 & 62.5 & 3.51 & 1.47 & 3.61 & 6.7 \\
\hline $\mathbf{P F}_{1}$ & $\begin{array}{c}264(277) \\
14.8(14.6)\end{array}$ & 1480 & 1.14 & 23.65 & 62.6 & 3.52 & 1.47 & 3.58 & 17.2 \\
\hline $\mathbf{P F}_{2}$ & $\begin{array}{c}292(307) \\
15.9(15.4)\end{array}$ & 1490 & 1.15 & 23.73 & 62.8 & 3.53 & 1.48 & 3.55 & 47 \\
\hline $\mathbf{P C l}_{1}$ & $\begin{array}{c}232(237) \\
5.0(4.8)\end{array}$ & 1500 & 1.14 & 24.18 & 62.1 & 3.49 & 1.46 & 3.56 & 3.1 \\
\hline $\mathbf{P C l}_{2}$ & $\begin{array}{c}142(160) \\
4.4(4.1)\end{array}$ & 1520 & 1.16 & 23.25 & 65.5 & 3.68 & 1.54 & 3.77 & 2.7 \\
\hline
\end{tabular}


repeat unit area $\left(\AA^{2}\right) ; e \cdot \mathrm{h}_{\mathrm{ru}}=\mathrm{A}_{\mathrm{ru}} / \mathrm{L}_{\mathrm{ru}}$ : spacing of backbones in the lamellar plane $(\AA) ; f \cdot \mathrm{q}_{\mathrm{ch}}=$ $\sigma_{\mathrm{ch}} / \mathrm{A}_{\mathrm{ru}}$ : chain packing ratio, $\sigma_{\mathrm{ch}}=42.5(1+7.5 \mathrm{E}-4(\mathrm{~T}-20))\left(\AA^{2}\right)$ is the cross-sectional area of a molten, branched chain; $g$. $\mathrm{h}_{\pi}$ : stacking distance from peak position $(\AA) ; \mathrm{I}\left(\mathrm{h}_{\pi}\right) / \mathrm{I}(001)$ : ratio of $\mathrm{h}_{\pi}$ and (001) peak intensities (\%); $\mathrm{L}_{\mathrm{ru}}=17.8 \AA$ is the calculated repeat unit length.

The combination of lamellar periodicity and geometrical data give access to the repeat unit area $A_{\mathrm{ru}}$, and the backbone spacing $h_{\mathrm{ru}}$, in the plane of the layers (see Table 3). The approximate agreement with the stacking distance $h_{\pi}$ shows that backbone planes are essentially vertical, and that the lateral extension of lamellae is therefore the lowest possible one. The ratio of about 1.5 with the cross-sectional area of chains is hence fixed and must be compensated by the spreading of the chains, which certainly contributes to stabilize the mesomorphic structures against crystallization. It should be stressed that $A_{\mathrm{ru}}$ and $h_{\pi}$ are remarkably constant in the polymer series (62-63 $\AA^{2}$ and 3.55-3.6 $\AA$, respectively), notwithstanding 5\% larger values for $\mathbf{P C l}_{\mathbf{2}}$. Finally, it appears that the polymer self-assemblies possess very similar geometries, despite the huge variation of the phase behaviors. A schematic representation is given in Figure 2.
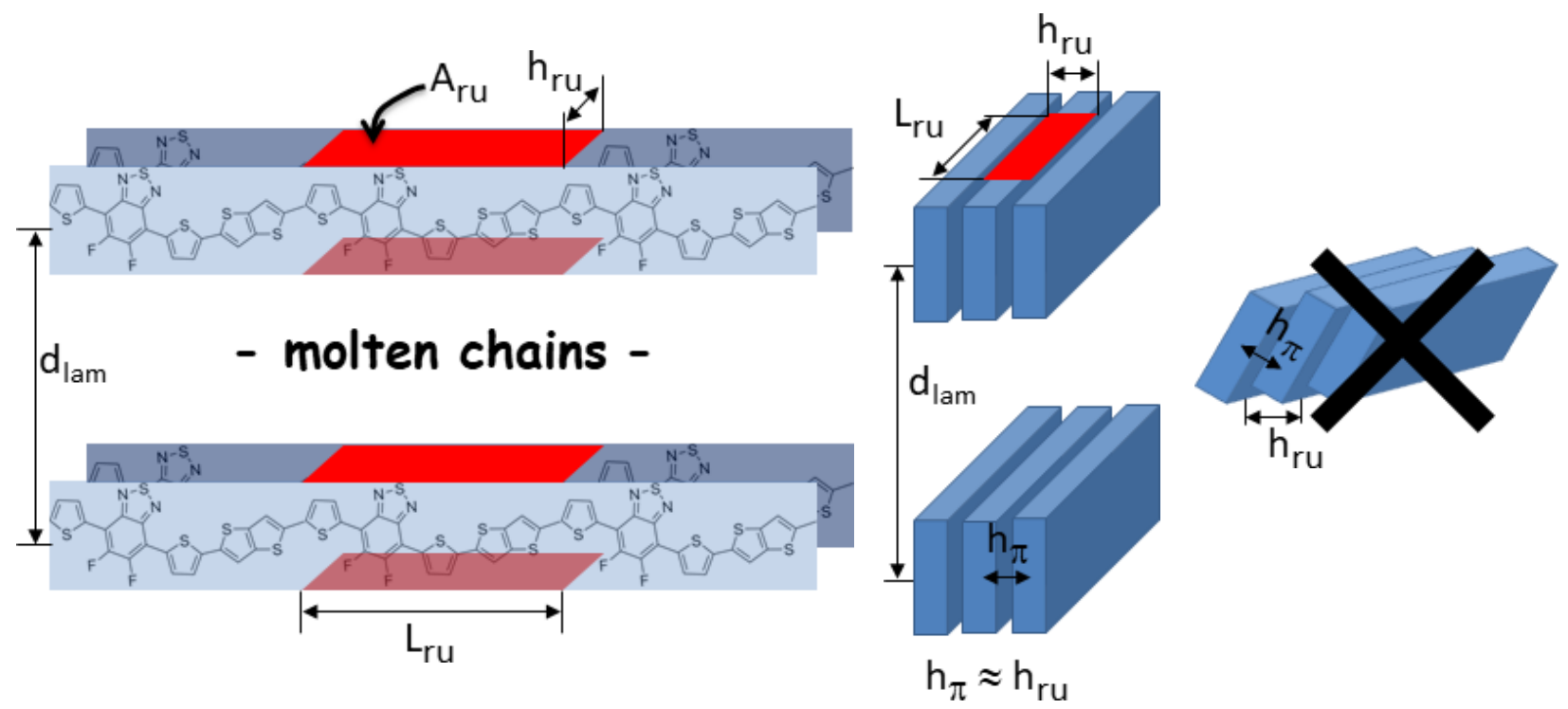
Figure 2. (Left) schematic representation of the lamellar system formed by polymers and definition of geometrical parameters $d_{\text {lam }}, A_{r u}, L_{r u}$ and $h_{r u}$. (Middle). View of the polymer lamellae along backbones, geometrical parameters and stacking distance $h_{\pi}$. (Right). Backbone planes are essentially vertical, leading to close $h_{r u}$ and $h_{\pi}$ values. (see Table 3 and text).

Apart from the additional in-plane periodicity appearing for fluorinated polymers (see below), the intensity of the $h_{\pi}$ peak is the principal feature varying in the patterns. Primarily, this feature reflects the amplitude of the electronic density modulation perpendicular to the backbone planes. Other things being equal, this amplitude comes down to the average degree of the $\pi$-stacked backbone overlap. For a comparative analysis of the intensity variations, the varying conditions of acquisition were addressed by the use of the intensity ratio with (100) peak, whose absolute intensity is only very slightly affected by the internal structure of the layers. Thereby, this intensity ratio considerably increases from $\mathbf{P X}_{\mathbf{0}}$ to fluorinated polymers, in consistency with the more cohesive self-assembly revealed by the phase behavior. For $\mathbf{P C l}_{\mathbf{1}}$, on the contrary, a decrease of the intensity ratio is observed, meaning that substitution with chlorine induces a lateral shift between facing backbones. The deleterious effect of this lateral shift on the cohesion of the self-assembly is compensated by other molecular interactions related to the presence of chlorine, so that this polymer exhibits an intermediate phase behavior. With the presence of a second halogen, the less cohesive self-assembly of $\mathbf{P} \mathbf{C l}_{\mathbf{2}}$ combines with lower overlapping and slightly increased backbone spacing, whereas phase transition data and peak intensity ratio follow the opposite trend when going from $\mathbf{P F}_{\mathbf{1}}$ to $\mathbf{P F}_{\mathbf{2}}$.

To summarize, the geometry of the lamellar structure hardly changes in this polymer series, but fluorination leads to a cohesive face-to-face stacking into layers, and chlorination to a less cohesive shifted stacking. 


\section{Optical and Electrochemical Properties}

It is now well-known in literature that halogenated polymers, and in particular fluorinated polymers, aggregate strongly in solution at room temperature. ${ }^{4,18,19}$ Most of the high performing halogenated polymers in OPV can only be solubilized at high temperature $\left(\approx 100^{\circ} \mathrm{C}\right)$. This feature is responsible of the high temperature process required for these thin-film polymer coatings. In order to characterize the impact of the number and nature of halogens on the solubility of our polymers, we carried out UV-vis measurements in orthodichlorobenzene (oDCB) solution as a function of the temperature. Several trends can be clearly identified from these measurements. In Figure 3 are reported the UV-absorption spectra of polymers recorded in $o$ DCB solution and for thin films. For each polymer, two main absorption bands are observed in solution, a characteristic commonly observed for D-A polymers. The first band at high energy can be attributed to a $\pi-\pi^{*}$ transition, while the high wavelength band is generally attributed to the intramolecular charge transfer (ICT) that occurs between electron rich and electron deficient units within the conjugated backbone.

To start with the fluorinated polymer series, it is worth noting that solubility decreases with increasing number of fluorine atoms on the benzothiadiazole unit. This is due to the many weak bonds created between fluorine atoms and neighboring heteroatoms. ${ }^{20,21,22,23}$ In practice, by lowering the temperature, the progressive aggregation of the polymer is observed and consequently, the UV-visible absorption of the solution is more and more similar to the one recorded for thin-films. This is clearly observable for $\mathbf{P F}_{2}$ that exhibits already at $65^{\circ} \mathrm{C}$ and below (Figure 3c), typical thin-film-like absorption spectra. The better solubility of $\mathbf{P F}_{\mathbf{1}}$, as compared to $\mathbf{P F}_{2}$, is illustrated by its lowest aggregation at moderate temperature which starts to take place below $55^{\circ} \mathrm{C}$ (Figure 3b). 
Along the chlorinated series, the behavior is far different and even opposite. Indeed, the more chlorine atoms in the backbone, the better is the solubility. As for $\mathbf{P X}_{\mathbf{0}}$, any of the chlorinated polymers show aggregation behavior in solution (Figures $3 \mathrm{a}$ and $3 \mathrm{~d}-\mathrm{e}$ ). This is a first indication of the steric congestion associated with chlorine substitution, probably coming from a backbone twisting. The delocalization between the benzothiadiazole electron-deficient unit and their neighboring electron-rich thiophene units could be probed by the relative intensity calculation of the two bands. Indeed, the ICT band at higher wavelengths is related somehow to the strength of the charge delocalization between respectively the electron-rich and the electron-deficient units. This delocalization is naturally affected by the backbone conformation. If a twist appears between the benzothiadiazole unit and the neighboring thiophene units, one should expect a delocalization decrease and therefore an ICT band intensity decrease. Upon calculation of the relative intensity ratio between the ICT band and the $\pi-\pi^{*}$ band (see Table 4 ) for all copolymers, it appears obvious that fluorination of the conjugated backbone increases the contribution of the ICT band, while in opposite, chlorination leads to a decrease of the ICT band intensity, as compared to the $\pi-\pi^{*}$ band intensity. This is an indirect confirmation of the twisted nature of the thiophene-benzothiadiazole-thiophene motif provided by chlorine substitution. 

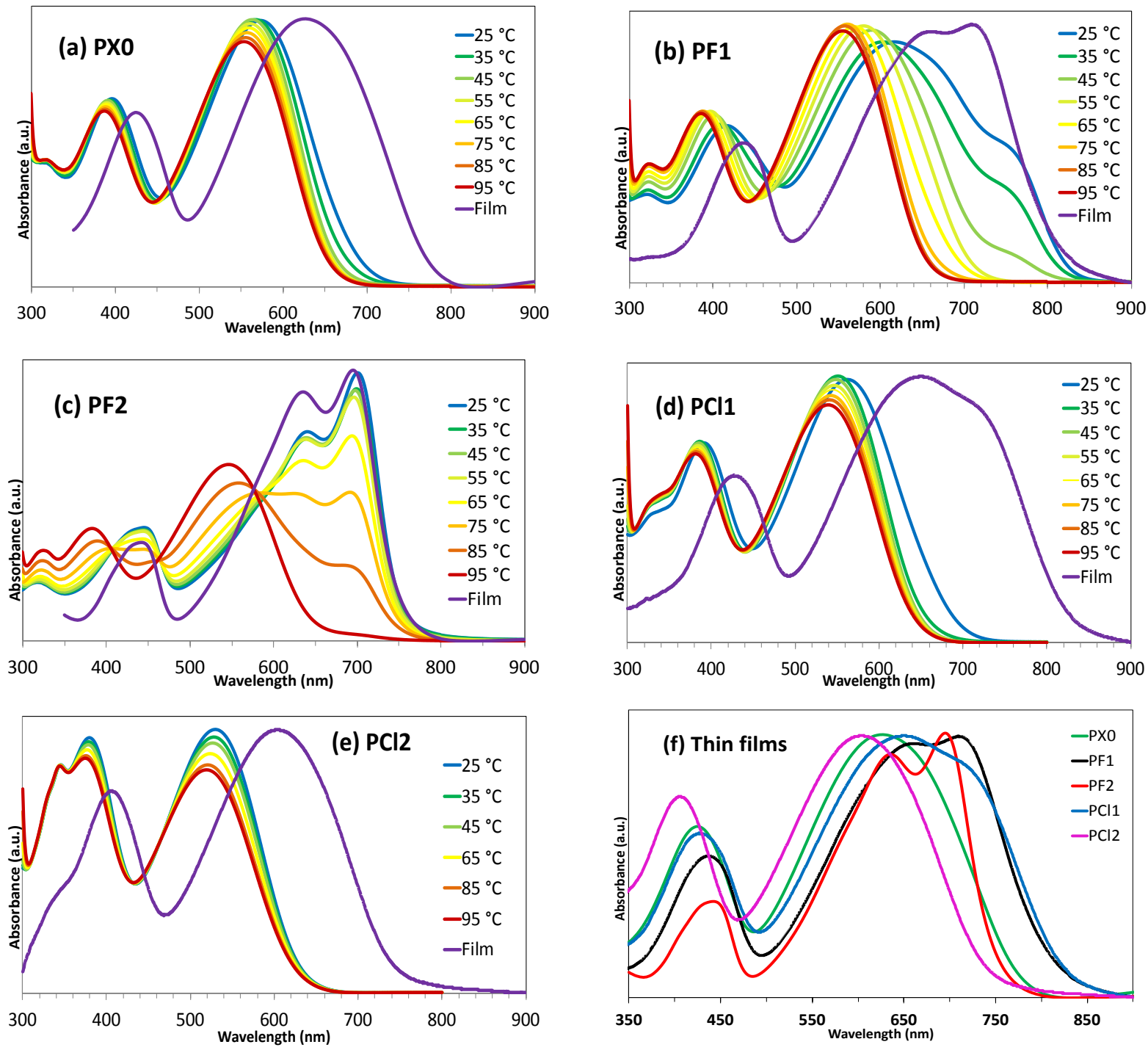

Figure 3. UV-Visible absorption spectra in $o$ DCB solution as function of temperature for (a) $\mathrm{PX}_{0}$; (b) $\mathrm{PF}_{1}$; (c) $\mathrm{PF}_{2}$; (d) $\mathrm{PCl}_{1}$; (e) $\mathrm{PCl}_{2}$ and (f) in thin-films.

Another indication that can be extracted from UV-Vis measurements in solution (at $95^{\circ} \mathrm{C}$, to ensure full solubility) is related to the intrinsic conjugation of different halogenated polymers (Figure S9 in ESI). Indeed, absorption maxima and absorption onsets are good indicators of polymer intrinsic conjugation. As already reported in several publications, the polymer substitution by halogen atoms does not lead to a conjugation extension. ${ }^{24}$ Due to a non- 
symmetrical decrease in the two frontier molecular orbitals (HOMO and LUMO), the opposite is even routinely observed. Thus, $\mathbf{P X}_{\mathbf{0}}$ exhibits in high-temperature solutions the highest delocalization (lowest bandgap), similar as for $\mathbf{P F}_{\mathbf{1}} \mathbf{P} \mathbf{P F}_{\mathbf{2}}$ shows a slight increase in bandgap, while both chlorinated polymers show even lowest delocalization. Such a bandgap increase after backbone chlorination, and compared to fluorinated analogues, has already been reported in literature. $^{25,26}$

Finally, the comparison of the solid-state absorption spectra allows to complete the previous observations (Figure 3f). In terms of delocalization, the two mono-halogenated polymers are distinguished by a significant bathochromic shift. At first sight, this strong absorption shift towards lower energies is surprising, especially for $\mathbf{P C l}_{\mathbf{1}}$, insofar as it contradicts the observations made in solution. However, it may relate to the occurrence of a dipolar moment along the conjugated polymer chains after asymmetric one-halogen substitution. Such dipolar moment is compatible with J-aggregate formation in the mono-halogenated polymer series, and it is reasonable, although hypothetical, to think that it could be responsible for the absorption bathochromic shifts. As a consequence, the mono-halogenated polymers exhibit the lowest optical bandgaps, around $1.5 \mathrm{eV}$. Then $\mathbf{P F}_{2}$, although showing a slightly higher bandgap, is in the same range as $\mathbf{P X}_{\mathbf{0}}$, around $1.6 \mathrm{eV}$. Finally, probably because of the chlorine-induced steric hindrance, $\mathbf{P C l}_{2}$ exhibits by far the highest optical bandgap in the series $(1.66 \mathrm{eV})$.

The vibronic structures in the solid-state spectra are the last features giving interesting information related to the solid-state polymer structures. We recently demonstrated that $\mathbf{P F}_{\mathbf{2}}$ could adopt two polymorphs with distinct stacks, either mixed stacking or segregated stacking. ${ }^{27}$ We, among others, establish the direct relationship between the vibronic progression into the ICT band of the absorption spectrum and the polymorph nature. Actually, the intensity of the $0-0$ 
component (the lowest energy vibronic band) is enhanced for the polymorph with long-range segregated $\pi$-stacks. After analyzing the current polymer series in light of this specific feature, one can clearly see that a new trend is emerging. Both $\mathbf{P} \mathbf{X}_{\mathbf{0}}$ and $\mathbf{P} \mathbf{P l}_{\mathbf{2}}$ do not show any vibronic features in solid state, highlighting their poor structuration within lamella stacks. $\mathbf{P C l}_{\mathbf{1}}$ exhibits a slight vibronic structure with the appearance of the 0-0 component but it remains below the intensity level of the 0-1 component (highest energy vibronic band), highlighting the probable mixed stacking of this mono-chlorinated polymer. Finally, only both fluorinated polymers present a $0-0$ band of higher intensity than the $0-1$ band and thus could be considered as mainly segregated stacked materials.

One can suggest that the steric hindrance induced by the chlorine atoms is responsible of the lowest segregated stacking tendency of the partially chlorinated polymers.

To sum up, and following the trend already observed in the structural property analysis, the more fluorine atoms grafted along the conjugated backbone, the more coherent and ordered the stacking of polymers is, while the opposite is true for the chlorinated series.

Table 4. optical and electrochemical properties of the synthesized copolymers

$\begin{array}{cccccccc} & \begin{array}{c}\text { Solution } \\ \lambda_{\text {abs }}(\mathrm{nm})^{a}\end{array} & \begin{array}{c}\text { ICT band } / \pi-\pi^{*} \\ \text { band }^{b}\end{array} & \begin{array}{c}\text { Thin film } \\ \lambda_{\text {abs }}(\mathrm{nm})\end{array} & \begin{array}{c}\text { Thin film } \\ \lambda_{\text {onset }}(\mathrm{nm})\end{array} & \mathrm{E}_{\mathrm{g}}{ }^{\text {opt }}(\mathrm{eV}) & \begin{array}{c}\mathrm{E}_{\text {ox }}(\mathrm{V}) / \mathrm{HOMO} \\ \text { level }(\mathrm{eV})\end{array} & \begin{array}{c}\text { LUMO } \\ \text { level }(\mathrm{eV})\end{array} \\ \mathbf{P X}_{\mathbf{0}} & 561 & 1.41 & 627 & 780 & 1.59 & 0.8 /-5.20 & -3.61 \\ \mathbf{P F}_{1} & 561 & 1.50 & 712 & 820 & 1.51 & 1.0 /-5.40 & -3.89 \\ \mathbf{P F}_{2} & 552 & 1.58 & 697 & 770 & 1.61 & 1.06 /-5.46 & -3.85 \\ \mathbf{P C l}_{1} & 543 & 1.27 & 653 & 835 & 1.48 & 1.0 /-5.40 & -3.92 \\ \mathbf{P C l}_{2} & 525 & 0.96 & 604 & 745 & 1.66 & 1.16 /-5.56 & -3.90\end{array}$

a. Calculated at $95^{\circ} \mathrm{C} ; b$. Calculated in solution at $95^{\circ} \mathrm{C}$

In order to estimate the energy levels of the polymers cyclic voltammetry (CV) on thin-films was performed. The oxidation potentials are shown in Figure S10 and the corresponding data along with the highest occupied molecular orbital ( $\mathrm{E}_{\text {номо }}$ ) and lowest unoccupied molecular orbital 
( $\left.E_{\text {LUMO }}\right)$ energy level values are summarized in Table 4. All potentials are referred to saturated calomel electrode (SCE) that was calibrated at $0.38 \mathrm{~V}$ versus the $\mathrm{Fc} / \mathrm{Fc}^{+}$system. ${ }^{28}$ All polymers exhibit reversible oxidation processes. The reduction peaks being difficult to record, the LUMO levels were extrapolated from the association of the optical bandgap and of the electrochemically measured HOMO level. As expected, because of the electron-withdrawing inductive effect of halogens, halogenated polymers show higher oxidation potentials as regards to the nonhalogenated $\mathbf{P} \mathbf{X}_{\mathbf{0}}$ polymer. Interestingly, $\mathbf{P} \mathbf{F}_{1}$ and $\mathbf{P} \mathbf{P C}_{\mathbf{1}}$, have similar $\mathrm{HOMO}$ levels. $\mathbf{P F}_{2}$, naturally presents a slightly deeper HOMO level, due to the addition of a second fluorine atom on the benzothiadiazole unit. Finally, $\mathbf{P C l}_{\mathbf{2}}$ exhibits a $0.10 \mathrm{eV}$ deeper $\mathrm{HOMO}$ level as regards to $\mathbf{P F}_{2}$. Such an amplification of the halogen electron-withdrawing effect when using chlorine atoms as compared to fluorine atoms has been already reported by Huang et al. and Yang and coworkers in particular. ${ }^{25,29}$

\section{DFT Calculations}

Density functional theory (DFT) calculations were carried out using SPARTAN 10 to probe the molecular and electronic properties of the polymers at the B3LYP/6-311 + G* level of theory in vacuum. To keep a reasonable calculation time, all alkyl side chains were replaced by methyl groups. The dihedral angle at both ends of the calculated structures was fixed to mimic the polymer rigidity and a perfect alternation was considered for the mono-halogenated benzothiadiazole polymers. Figure S11 displays the optimized molecular conformation for the different polymers.

The dihedral angles between the electron-deficient benzothiadiazole unit and the neighboring electron-rich thiophene units as well as between the thiophene and thieno[3,2-b]thiophene units 
are substantially depending on the polymer considered. The definition of each dihedral angle can be found in Figure 4, while the measured angles are reported in Table 5.

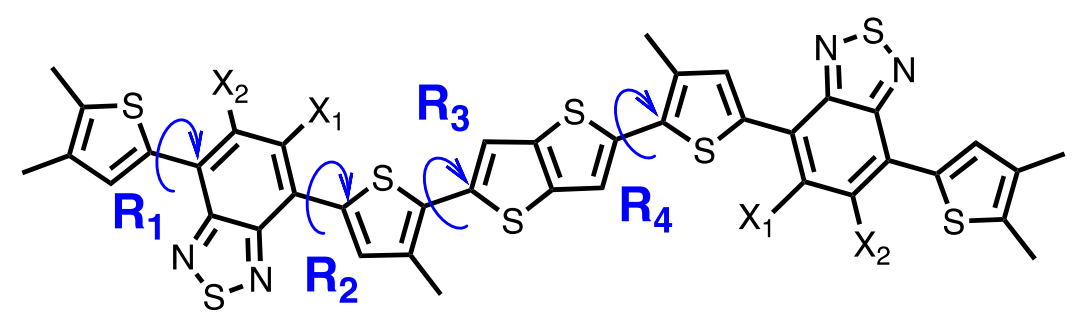

Figure 4. Definition of the dihedral angles using the example of $\mathrm{PCl}_{1}$.

Note that for $\mathbf{P X}_{\mathbf{0}}, \mathbf{P F}_{\mathbf{2}}$ and $\mathbf{P C l}_{\mathbf{2}}, \mathbf{R}_{1}$ and $\mathrm{R}_{2}$ are equal while a difference between those two dihedral angles is expected for $\mathbf{P F}_{\mathbf{1}}$ and even more for $\mathbf{P C l}_{\mathbf{1}}$ with a monomer backbone bearing one sterically hindering chlorine atom.

Table 5. calculated dihedral angles (as defined in Figure 4) and HOMO, LUMO, gap energy and dipole.

$\begin{array}{ccccccccc} & \mathrm{R} 1\left(^{\circ}\right) & \mathrm{R} 2\left(^{\circ}\right) & \mathrm{R} 3\left(^{\circ}\right) & \mathrm{R} 4\left(^{\circ}\right) & \begin{array}{c}\mathrm{HOMO} \\ (\mathrm{eV})\end{array} & \begin{array}{c}\mathrm{LUMO} \\ (\mathrm{eV})\end{array} & \begin{array}{c}\mathrm{E}_{\mathrm{g}} \\ (\mathrm{eV})\end{array} & \begin{array}{c}\text { Dipole } \\ (\mathrm{Dye})\end{array} \\ \mathbf{P X}_{\mathbf{0}} & 3 \pm 2 & 3 \pm 2 & 11 \pm 1 & 11 \pm 1 & -4.72 & -2.69 & 2.03 & 0.13 \\ \mathbf{P F}_{1} & 1.5 \pm 0.3 & 0.8 \pm 0.3 & 12.0 \pm 0.6 & 12.0 \pm 0.6 & -4.76 & -2.76 & 2.00 & 3.07 \\ \mathbf{P F}_{2} & 0.9 \pm 0.6 & 0.9 \pm 0.6 & 11.5 \pm 0.9 & 11.5 \pm 0.9 & -4.80 & -2.78 & 2.02 & 0.44 \\ \mathbf{P C l}_{1} & 1.2 \pm 0.9 & 34.5 \pm 2 & 24.7 & 9.3 & -4.87 & -2.76 & 2.11 & 2.04 \\ \mathbf{P C l}_{2} & 43 \pm 4 & 43 \pm 4 & 24.4 & 19.8 & -5.01 & -2.79 & 2.22 & 0.41\end{array}$

A certain planarization of the backbone around the benzothiadiazole unit is observed in polymers containing fluorine atoms $\left(\mathbf{P F}_{\mathbf{1}}\right.$ and $\mathbf{P F}_{\mathbf{2}}$ as compared to $\left.\mathbf{P} \mathbf{X}_{\mathbf{0}}\right)$. This observation is in line with the usually reported planarization of fluorinated polymer backbones. ${ }^{4}$ As expected, the chlorinated 
polymers systematically show higher dihedral $R_{1}$ and $R_{2}$ angles (on the chorine side for $\mathbf{P C l}_{1}$ ) due to the chlorine atom steric hindrance. The $\mathrm{R}_{3}$ dihedral angle is also higher in the chlorinated polymers and the torsion of the backbone is really pronounced in $\mathbf{P C l} \mathbf{l}_{\mathbf{1}}$ and $\mathbf{P C l}_{\mathbf{2}}$. Such a backbone twisting, in the case of chlorinated polymers, would be fully in line, not only with the phase transition temperature evolution, as observed from DSC measurements, but also with all the UV-vis measurements. It explains also the relative ICT to $\pi$ - $\pi^{*}$ band intensity ratio evolution in the polymer series (Table 4). The backbone torsion impacts also the calculated HOMO and LUMO levels and delocalization (Table 5).

The general trend measured by $\mathrm{CV}$ is also observed in the calculations: the HOMO level gets deeper and deeper when going from $\mathbf{P X}$ to $\mathbf{P F}$, from $\mathbf{P F} \mathbf{F}_{\mathbf{1}}$ to $\mathbf{P} \mathbf{F}_{2}$, from $\mathbf{P F} \mathbf{F}_{\mathbf{2}}$ to $\mathbf{P C l}_{\mathbf{1}}$ and finally from $\mathbf{P C l}_{\mathbf{1}}$ to $\mathbf{P C l}_{\mathbf{2}}$ (see Table 5). The LUMO estimated as the HOMO measured by CV plus the optical band-gap (Table 4) is also consistent with the calculated LUMO level with an almost constant LUMO level for all halogenated polymers deeper by $0.1 \mathrm{eV}$ when compared to the $\mathbf{P X}_{\mathbf{0}}$ LUMO. On the one hand, the deepening of the HOMO when going from $\mathbf{P X} \mathbf{X}_{\mathbf{0}}$ to $\mathbf{P F}_{\mathbf{1}}$ to $\mathbf{P F}_{\mathbf{2}}$ is due to the addition of the very electronegative fluorine atom. On the other hand, the deepening of the $\mathrm{HOMO}$ when going from $\mathbf{P} \mathbf{F}_{\mathbf{2}}$ to $\mathbf{P C l} \mathbf{l}_{\mathbf{1}}$ to $\mathbf{P C l} \mathbf{l}_{\mathbf{2}}$ is probably due to the synergistic effect of the chlorine electronegativity and of the induced backbone rotation when adding chlorine atom that hinder the molecular hybridization of the different moieties (as observed on the HOMO delocalization in ESI for instance).

Finally, the calculated dipole moment (Table 5) confirms the occurrence of a strong dipolar moment along the conjugated polymer chains on disymmetrically halogenated polymers $\left(\mathbf{P C l}_{\mathbf{1}}\right.$ and $\mathbf{P F} \mathbf{F}_{1}$. This dipolar moment is compatible with the hypothesis of J-aggregate formation, as 
previously formulated, and it may explain their absorption bathochromic shifts in solid state compared to the other polymers of this series.

\section{Charge transport characterizations}

Space charge limited current (SCLC) devices have been used to investigate hole mobility in the direction perpendicular to the substrate (see Table 6 and Figure S12). Obviously and as expected from previous analysis, the trends between chlorinated and fluorinated polymers are opposite. When compared to the non-halogenated $\mathbf{P} \mathbf{X}_{\mathbf{0}}$ polymer, fluorinated $\mathbf{P} \mathbf{F}_{\mathbf{1}}$ and $\mathbf{P} \mathbf{F}_{\mathbf{2}}$, both exhibit significantly increased hole mobilities of about $10^{-3}$ and almost $10^{-2} \mathrm{~cm}^{2} \cdot \mathrm{V}^{-1} \cdot \mathrm{s}^{-1}$, respectively. These high SCLC mobilities are due to the backbone planarization and enhanced $\pi$-stacking intensity observed in fluorinated polymers as the halogen weak bonds improve the solid-state structuration of these two polymers, as compared to $\mathbf{P X}$. Looking at chlorinated polymers, $\mathbf{P C l}_{\mathbf{1}}$ has a SCLC hole mobility $\left(5 \times 10^{-4} \mathrm{~cm}^{2} . \mathrm{V}^{-1} . \mathrm{s}^{-1}\right)$ twice as high as $\mathbf{P X}_{\mathbf{0}}$ but one decade higher than the $\mathbf{P C l}_{2}$ hole mobility. This illustrates the lower structural ordering when too many chlorine atoms are grafted along the conjugated skeleton.

Table 6. Hole mobility values and optimized photovoltaic parameters (average values on 8 diodes)

\begin{tabular}{|c|c|c|c|c|c|c|c|c|c|}
\hline & $\begin{array}{c}\text { Hole } \\
\text { mobility } \\
\left(\mathrm{cm}^{2} \cdot \mathrm{V}^{-1} \cdot \mathrm{s}^{-1}\right)\end{array}$ & $\begin{array}{c}\text { OPV } \\
\text { device } \\
\text { structure }\end{array}$ & $\begin{array}{c}\mathrm{AL} \\
\text { processing } \\
\text { temperatur } \\
\mathrm{e}\end{array}$ & $\begin{array}{c}\text { Polymer : } \\
\mathrm{PC}_{71} \mathrm{BM} \\
\text { ratio }\end{array}$ & Additive & $\begin{array}{l}\mathrm{V}_{\mathrm{oc}} \\
(\mathrm{V})\end{array}$ & $\begin{array}{c}\mathbf{J}_{\mathrm{sc}} \\
\left(\mathrm{mA} \cdot \mathrm{cm}^{-2}\right)\end{array}$ & $\begin{array}{l}\mathrm{FF} \\
(\%)\end{array}$ & $\begin{array}{l}\text { PCE } \\
(\%)\end{array}$ \\
\hline $\mathbf{P X}_{0}$ & $2.7 \times 10^{-4}$ & inverted & $100^{\circ} \mathrm{C}$ & $1: 1.5$ & DIO 3\% & 0.65 & 8.6 & 57 & $3.35(3.2)$ \\
\hline $\mathbf{P F}_{1}$ & $1.3 \times 10^{-3}$ & inverted & $100^{\circ} \mathrm{C}$ & $1: 1.5$ & DPE 3\% & 0.65 & 16.0 & 71.1 & 7.76 (7.62) \\
\hline $\mathbf{P F}_{2}$ & $7.0 \times 10^{-3}$ & inverted & $100^{\circ} \mathrm{C}$ & $1: 1.5$ & - & 0.75 & 19.1 & 71.3 & $10.5(10.2)$ \\
\hline $\mathbf{P C l}_{1}$ & $5.4 \times 10^{-4}$ & inverted & $100^{\circ} \mathrm{C}$ & $1: 1.2$ & DIO 3\% & 0.71 & 6.5 & 37 & $1.88(1.73)$ \\
\hline $\mathbf{P C l}_{2}$ & $4.0 \times 10^{-5}$ & inverted & $100^{\circ} \mathrm{C}$ & $1: 1.2$ & DIO 3\% & 0.92 & 2.3 & 28 & $0.67(0.60)$ \\
\hline $\mathbf{P F}_{1}$ & & inverted & $70^{\circ} \mathrm{C}$ & $1: 1.5$ & DPE 3\% & 0.64 & 16.4 & 70.2 & $7.72(7.44)$ \\
\hline $\mathbf{P F}_{1}$ & & standard & $70^{\circ} \mathrm{C}$ & $1: 1.5$ & DPE $3 \%$ & 0.65 & 16.9 & 70.1 & $8.01(7.70)$ \\
\hline
\end{tabular}


In order to confirm this trend, we also probed the hole mobilities by organic field effect transistor (OFET) devices (see Figure S13-S17 and table S1). Although mobility is probed in the direction parallel to the substrate and with a higher charge-carrier concentration, we have found exactly the same trends with mobility ranging from $10^{-4}$ for the lowest to $10^{-2} \mathrm{~cm}^{2} \cdot \mathrm{V}^{-1} \cdot \mathrm{s}^{-1}$ for the highest.

\section{Organic photovoltaic performances}

$\mathbf{P F}_{2}$ and $\mathbf{P X}_{\mathbf{0}}$ polymers have been previously investigated in inverted configuration solar cells (ITO/ZnO/polymer:PC $\left.{ }_{71} \mathrm{BM} / \mathrm{MoO}_{3} / \mathrm{Ag}\right){ }^{11}{ }^{11}$ Therefore herein, OPV performances of all polymers have been first investigated under identical configuration, using $\mathrm{PC}_{71} \mathrm{BM}$ as electronwithdrawing material, $o$ DCB as deposition solvent and keeping similar high deposition temperatures $\left(95-100^{\circ} \mathrm{C}\right)$. Two standard additives were tested for each polymer in different amounts, DIO and DPE, respectively. The corresponding photovoltaic parameters for the optimized devices for each polymer system (short circuit current density $J_{s c}$, open circuit voltage $V_{o c}$, and fill factor $F F$ ) are summarized in Table 6. Experimental details and examples of J-V curves can be found in the supporting information (Figures S18 and S19).

First, one can note that PCEs follow a very similar trend to the hole mobility values previously measured. Indeed, $\mathbf{P F}_{2}$ exhibits the highest PCE of $10.5 \%$, with a remarkable $F F$ and a very high $J_{s c}$, illustrating the high SCLC hole mobility. Not surprisingly, $\mathbf{P F}_{\mathbf{1}}$ provides the second best OPV performance with a PCE of approximately $7.8 \%$. Interestingly, we recorded a really similar and high FF (72\% for $\mathbf{P F}_{\mathbf{1}}$ and for $\mathbf{P F}_{2}$ ). The decrease in efficiency for $\mathbf{P F} \mathbf{F}_{\mathbf{1}}$ compared to $\mathbf{P F}_{\mathbf{2}}$ is related to the lower $J_{s c}$ and $V_{o c}$, probably due to the limited hole mobility and the lower ionization potential, respectively. Another difference (explained below by GIWAXS analysis) is 
related to the need of additive (3\% in volume of DPE) to achieve high performances with $\mathbf{P F}_{\mathbf{1}}$ when $\mathbf{P} F_{2}$ performs nicely without requiring additive.

Unfortunately, both chlorinated polymers show very low OPV performances, despite a process optimization. As chlorine atoms are added, there is a clear decrease in PCE, related to the joint decrease in $J_{s c}$ and $F F$. Actually, only the $V_{o c}$, directly related to the polymer HOMO levels stays in good agreement with the previous electrochemical measurements. Indeed, by increasing the polymer chlorine substitution, one can see a clear $V_{o c}$ increase, related to the subsequent deepening of the HOMO level.

Nevertheless, $\mathbf{P} \mathbf{F}_{\mathbf{1}}$ has an interesting feature compared to $\mathbf{P} \mathbf{F}_{\mathbf{2}}$ that we have not yet taken advantage of: its better solubility. To investigate this specific issue, we modified slightly the process conditions by decreasing the deposition temperature (temperature of the solution + temperature of the substrate). We chose $70^{\circ} \mathrm{C}$, temperature for which $\mathbf{P F}_{\mathbf{1}}$ is still completely soluble (i.e. no aggregation detectable by UV-vis absorption), when PF2 is already aggregated (gelled solution). Interestingly, while the gelled $\mathbf{P F} 2$ solution does not allow a homogeneous thin film to be deposited, the $\mathbf{P F}_{\mathbf{1}}$ solution remains liquid and the film formed appears as homogeneous as at $100^{\circ} \mathrm{C}$. More significantly, OPV performances remain very similar to the one measured at $100^{\circ} \mathrm{C}$. This result demonstrates that by reducing the number of fluorine atoms (from two to one) on the benzothiadiazole unit, OPV performances are slightly reduced, but the system allows a much lower process temperature and therefore, a better compatibility with industrialization (e.g. roll-to-toll or ink-jet printing processes), and it also widens the processing window, underlying an easier reproducibility. Finally, it has to be noted that $\mathbf{P F}_{\mathbf{1}}: \mathrm{PC}_{71} \mathrm{BM}$ blends have been tested in standard architecture devices (ITO/PEDOT:PSS/polymer:PC ${ }_{71} \mathrm{BM} / \mathrm{Ca} / \mathrm{Al}$ ). 
The even higher PCE of about $8 \%$ obtained in this configuration at $70^{\circ} \mathrm{C}$ illustrates very well this broad process condition window.

\section{Thin film morphology of polymers and blends with $\mathrm{PC}_{71} \mathrm{BM}$}

GIWAXS was employed to further investigate the macromolecular packing in neat polymer and in optimized blend films. Thin films were spin-coated in conditions of SCLC and OPV device fabrication, for neat polymer and blend, respectively.

The presence of the scattering signatures of molten chains $h_{\mathrm{ch}}$, and $\pi$-stacked backbones $h_{\pi}$, together with the lamellar orders $(h 00)$, confirms that the neat polymer films have the same structures as bulk polymers in their frozen lamellar mesophases (see figures 1, 4 and S10). Practically, the main variation is a slightly larger lateral expansion of lamellae with ca. 5\% increased $A_{\mathrm{ru}}$ values (see table 7). Films are well oriented with two major populations of domains: face-on for the one whose $\pi$-stacking direction is close to the film normal, and edge-on when this direction is close to the film plane. OPV requires the face-on configuration for charge extraction and its proportion is here close to $50 \%$ for $\mathbf{P F}_{\mathbf{1}}, \mathbf{P F}_{\mathbf{2}}$ and $\mathbf{P C l}_{\mathbf{1}}$. For $\mathbf{P C l} \mathbf{l}_{\mathbf{2}}$, it drops to $25 \%$ and charge transport might further be limited by the efficiency of conduction pathways, given the low cohesive stacking of backbones for this polymer revealed by the weak $h_{\pi}$ peak.
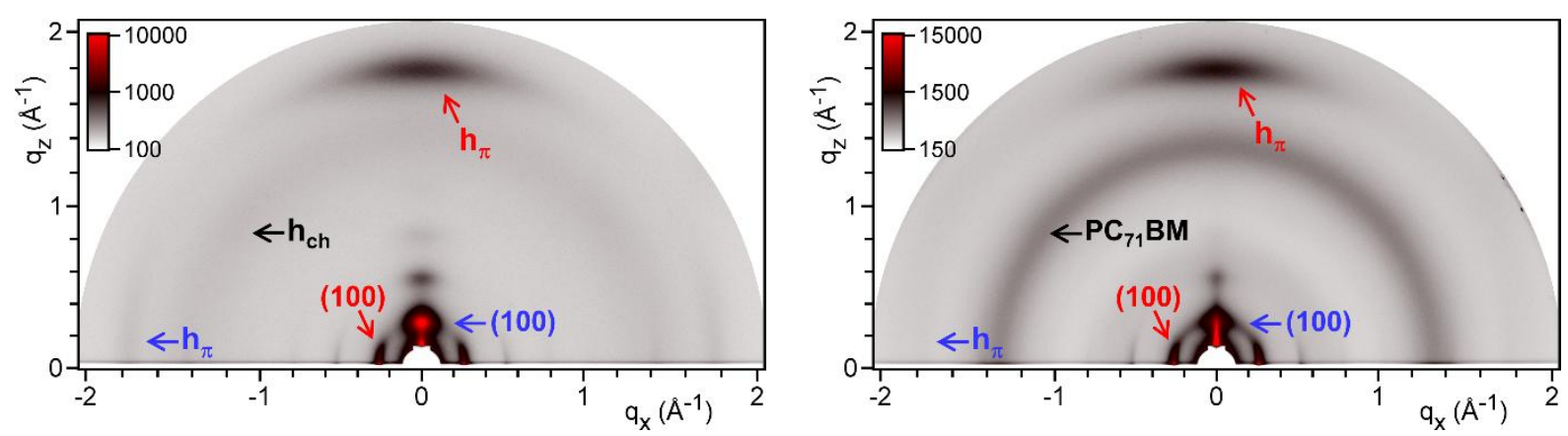

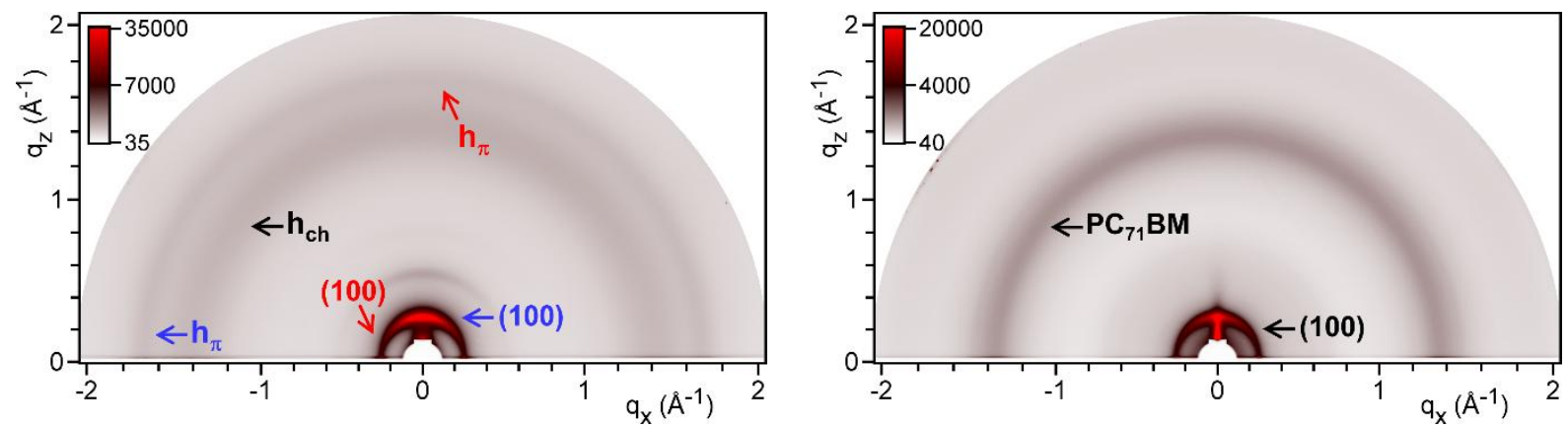

Figure 5. GIWAXS patterns of thin films deposited with solvent, bottom layer and conditions of OPV device fabrication: neat $\mathbf{P F}_{2}$ (top, left), $\mathbf{P F}_{2}: \mathrm{PC}_{71} \mathrm{BM}$ blend at 1:1.5 ratio (top, right), neat $\mathbf{P C l}_{2}$ (bottom, left), $\mathbf{P C l}_{2}: \mathrm{PC}_{71} \mathrm{BM}$ blend at 1:1.2 ratio (bottom, right). Two major populations of domain orientation can be distinguished, namely red $(h 00)$ and $h_{\pi}$ spots for face-on, and blue (h00) and $h_{\pi}$ spots for edge-on. $\mathbf{P F}_{\mathbf{2}}$ shows same structure and morphology in neat film and in blend, whereas higher order $(h 00)$ and $\mathrm{h}_{\pi}$ vanish for the $\mathbf{P C l}_{\mathbf{2}}$ blend. The patterns for $\mathbf{P} \mathbf{F}_{\mathbf{1}}, \mathbf{P C l}_{\mathbf{1}}$, $\mathbf{P C}_{71} \mathbf{B M}$ and their blends are displayed in Figure S20; radial and azimuthal profiles for quantitative analysis were plotted in Figures S21 and S22.

Table 7. Structure and morphology of thin films of polymers and blends with PC71BM as obtained from GIWAXS patterns in Figures 4 and S10. Polymer domains are in a state similar to the Lam phase of bulk polymers.

\begin{tabular}{|c|c|c|c|c|c|c|c|c|c|c|}
\hline & \multirow[b]{2}{*}{ solvent } & \multicolumn{4}{|c|}{ Neat polymer } & \multicolumn{5}{|c|}{ Polymer:PC ${ }_{71} \mathrm{BM}$ blend (x:y) } \\
\hline & & $\begin{array}{l}d_{\mathrm{lam}} \\
(\AA)^{a}\end{array}$ & $\begin{array}{c}A_{\mathrm{ru}} \\
\left(\AA^{2}\right)^{a}\end{array}$ & $\begin{array}{c}h_{\pi} \\
(\AA)\end{array}$ & $\begin{array}{c}\text { Face- } \\
\text { on } \\
(\%)^{b}\end{array}$ & $\mathrm{x}: \mathrm{y}$ & $\begin{array}{l}d_{\mathrm{lam}} \\
(\AA)^{a}\end{array}$ & $\underset{\left(\AA_{\mathrm{ru}}^{2}\right)^{a}}{A_{\text {a }}}$ & $\begin{array}{c}h_{\pi} \\
(\AA)\end{array}$ & $\begin{array}{c}\text { Face- } \\
\text { on } \\
(\%)^{b}\end{array}$ \\
\hline $\mathbf{P F}_{1}$ & $o \mathrm{DCB}+3 \% \mathrm{DPE}$ & 22.6 & 66 & 3.53 & 52 & $1: 1.5$ & 22.3 & 66 & 3.51 & 76 \\
\hline $\mathbf{P F}_{2}$ & $o \mathrm{DCB}$ & 23.1 & 65 & 3.50 & 47 & $1: 1.5$ & 23.0 & 65 & 3.49 & 58 \\
\hline $\mathbf{P C l}_{1}$ & $o \mathrm{DCB}+3 \% \mathrm{DIO}$ & 22.9 & 65 & 3.56 & 54 & $1: 1.2$ & 23.1 & 65 & 3.57 & 56 \\
\hline $\mathbf{P C l}_{2}$ & $\mathrm{CB}+3 \% \mathrm{DIO}$ & 23.2 & 65 & 3.67 & 25 & $1: 1.2$ & 23.2 & 65 & - & - \\
\hline
\end{tabular}

a. $d_{\text {lam }}, A r u$ and $h_{\pi}$ are defined as in Table $3 ; b$. \% Face-on is the proportion of face-on domains, defined as those whose $\pi$-stacking direction is tilted by less than $45^{\circ}$ from film normal. 
Relevant for OPV are the ultimate structure and morphology of the blends with the acceptor material, indeed. Blending obviously altered the structure of $\mathbf{P C l}_{\mathbf{2}}$ domains, as shown by the disappearance of all peaks, except the fundamental lamellar order. The collapse of higher orders and of $h_{\pi}$ means that layer interfaces have become irregular and that the $\pi$-stacking is altered. The most likely cause is the presence of impurity, i.e. in this instance, $\mathrm{PC}_{71} \mathrm{BM}$ incorporation in polymer domains. For $\mathbf{P C l}_{\mathbf{1}}$, the neat polymer signals are maintained in the blend, but the weaker $h_{\pi}$ peak might be the sign of a purity issue. For $\mathbf{P F}_{2}$ and $\mathbf{P F}_{1}$, there are no differences between polymer signals of neat materials and blends. Beyond the structure, the morphology of polymer domains is of course influenced by the blending: major face-on and edge-on populations are still identifiable, although there is contribution from intermediate orientations. Surprisingly, the proportion of rather face-on oriented domains (i.e. the one with $\pi$-stacking direction tilted by less than $45^{\circ}$ ), is even higher for $\mathbf{P F}_{\mathbf{1}}$ and $\mathbf{P F}_{2}$ while rather constant for $\mathbf{P C l}_{\mathbf{1}}$. The important role of the solvent additive should also be emphasized. $\mathbf{P F}_{1}: \mathrm{PC}_{71} \mathrm{BM}$ film from pure $o \mathrm{DCB}$ (i.e. without DPE) was poorly oriented and overall face-on proportion was $20 \%$ lower as with presence of additive, explaining pretty well the additive requirement for high OPV performances. Then, $\mathbf{P F}_{1}: \mathrm{PC}_{71} \mathrm{BM}$ film from $o \mathrm{DCB}$ could be structured in presence of DIO, but remains amorphous without additive (see figures ESI-S13).

To summarize, GIWAXS measurements support previous analyses, including OPV characterization of these polymers. Indeed, the structure and orientation of the $\mathbf{P F}_{\mathbf{1}}, \mathbf{P F}_{\mathbf{2}}$ and $\mathbf{P C l}_{\mathbf{1}}$ polymers are a priori favorable for OPV, contrarily to the one of $\mathbf{P C l}_{\mathbf{2}}$ films. However, upon blending with $\mathrm{PC}_{71} \mathrm{BM}$, issues are emerging in terms of domain purity and structural cohesion for $\mathbf{P C l}_{\mathbf{1}}$ films, easily correlated to the significantly lower PCE. 


\section{Conclusion}

In summary, starting from a performing and well-known fluorinated D-A polymer, called $\mathbf{P F}$, we designed, synthesized and investigated new halogenated polymers, by varying not only the number of halogen $\left(\mathbf{P F}_{\mathbf{1}}\right)$ atoms within the conjugated backbone, but also their nature $\left(\mathbf{P C l}_{\mathbf{1}}\right.$ and $\mathbf{P C l}_{2}$ ), using both fluorine and chlorine atoms. The extensive experimental and theoretical study of these new polymers, using the non-halogenated polymer as reference $\left(\mathbf{P X}_{\mathbf{0}}\right)$, allowed us to rationalize the impact of these modifications. Thus, if the halogen number and nature modified slightly the energy levels of these polymers, the main impact is related to the structural properties in solid state and morphological behaviors in blend with the electron acceptor component. DSC, UV-vis absorption characterizations and powder X-ray diffraction analysis, clearly highlight the impact of the significantly higher steric hindrance of chlorine atoms relative to fluorine atoms. This steric congestion leads to a slight backbone twist, a much less ordered $\pi$-stacking and finally to a weaker solid-state cohesion. In opposite, the planarization of the backbone is observed when the amount of fluorine increases (from $\mathbf{P X}$ to $\mathbf{P F}$ and $\mathbf{P F}_{\mathbf{2}}$ ). These assertions are also consistent with density functional theory (DFT) calculations on a single molecule. Further, complementary grazing incident X-Ray analysis shows a significant proportion of face-on orientation on the substrate of the backbone for the fluorinated series and for $\mathbf{P C l}_{\mathbf{1}}$. However, due to a stronger solid-state cohesion, the structural order is less affected upon blending with $\mathrm{PC}_{71} \mathrm{BM}$ for the fluorinated series, while the reference polymer $\mathbf{P X} \mathbf{X}_{\mathbf{0}}$ as well as $\mathbf{P C l}_{\mathbf{1}}$ are strongly affected by the presence of the electron-accepting molecule. Finally, upon blending, $\mathbf{P C l}_{\mathbf{2}}$-based thin films exhibit the disappearance of all X-ray diffraction peaks, except the fundamental lamellar order, explaining the very low measured PCEs. All these analyses are fully consistent with charge 
transport and photovoltaic properties measured after careful optimization of each thin film and each blend.

Finally, $\mathbf{P F}_{\mathbf{1}}$ is an interesting candidate for solar modules production. Indeed, most of the properties of $\mathbf{P F}_{\mathbf{2}}$ that are favorable for photovoltaic applications are preserved for $\mathbf{P F}_{\mathbf{1}}$ but its lower tendency to aggregate in solution allows to process it at a lower temperature. Indeed, while $\mathbf{P F}_{2}$ cannot be processed at temperatures lower than $90^{\circ} \mathrm{C}, \mathbf{P F}_{\mathbf{1}}$ can be processed at $70^{\circ} \mathrm{C}$ with a power conversion efficiency as high as $7-8 \%$. Such a processing temperature is compatible with large-area modules deposition techniques like Roll-to Roll or inkjet printing. Further, using $\mathbf{P F}_{\mathbf{1}}$ instead of $\mathbf{P F}_{2}$ widens the temperature-processing window, a very important property while considering the industrial elaboration of BHJ solar modules.

\section{Corresponding Author}

*E-mail: leclercn@unistra.fr

\section{Notes}

The authors declare no competing financial interest.

\section{Acknowledgements}

The authors gratefully acknowledge funding from INTERREG Upper Rhine (European Regional Development Fund), the Ministries for Research of Baden-Württemberg, RheinlandPfalz and the Region Grand Est provided a funding in the framework of the Science Offensive Upper Rhine program (PROOF project). The authors also thank Pohang Accelerator Laboratory (PAL) for giving the opportunity to perform the GIWAXS measurements, MEST and POSTECH for supporting these experiments, Dr Hyungju Ahn for adjustments and help, and other 
colleagues from the 9A USAXS beamline for assistance. The authors also thanks Dr. Emeric Wasielewski, engineer on the Cronenbourg NMR platform, for the high temperature experiments.

\section{A Supporting Information is available free of charge on the ACS Publications website. It includes all details about characterizations; polymer NMR spectra; TGA curves; SWAXS patterns on powder; UV-Visible absorption spectra in $o$-DCB solution at $95^{\circ} \mathrm{C}$; Cyclic voltamperogramms; polymer DFT structures; SCLC current-voltages characteristics; OFET characterizations; OPV J(V) curves; complementary XRD data.}

\section{References}

(1) Lu, L.; Zheng, T.; Wu, Q.; Schneider, A. M.; Zhao, D.; Yu, L., Recent Advances in Bulk Heterojunction Polymer Solar Cells. Chem. Rev., 2015, 115, 12666-12731.

(2) Yuan, J.; Zhang, Y.; Zhou, L.; Zhang, G.; Yip, H.-L.; Lau, T.-K.; Lu, X.; Zhu, C.; Peng, H.; Johnson, P. A.; Leclerc, M.; Cao, Y.; Ulanski, J.; Li Y.; Zou, Y. Single-Junction Organic Solar Cell with over 15\% Efficiency Using Fused-Ring Acceptor with Electron-Deficient Core. Joules, 2019, 3, 1140-1151.

(3) Cui, Y.; Yao, H.; Zhang, J.; Zhang, T.; Wang, Y.; Hong, L.; Xian, K.; Xu, B.; Zhang, S.; Peng, J.; Wei, Z.; Gao, F.; Hou, J. Over $16 \%$ efficiency organic photovoltaic cells enabled by a chlorinated acceptor with increased open-circuit voltages. Nat. Commun., 2019, 10, 2515.

(4) Leclerc, N.; Chávez, P.; Ibraikulov, O. A.; Heiser T.; Lévêque, P. Impact of backbone fluorination on $\pi$-conjugated polymers in organic photovoltaic devices: A Review. Polymers, 2016, 8, 11. 
(5) Tang, M. L.; Hak Oh, J.; Reichardt, A. D.; Bao, Z. Chlorination: A General Route toward Electron Transport in Organic Semiconductors. J. Am. Chem. Soc., 2009, 131, 3733-3740.

(6) Lei, T.; Dou, J.-H.; Ma, Z.-J.; Liu, C.-J.; Wang, J.-Y.; Pei, J. Chlorination as a useful method to modulate conjugated polymers: balanced and ambient-stable ambipolar highperformance field-effect transistors and inverters based on chlorinated isoindigo polymers. Chem. Sci., 2013, 4, 2447-2452.

(7) Qu, S.; Wang, H.; Mo, D.; Chao, P.; Yang, Z.; Li, L.; Tian, L.; Chen, W.; He, F. Fine Tuning of Open-Circuit Voltage by Chlorination in Thieno[3,4-b]thiophene-Benzodithiophene Terpolymers toward Enhanced Solar Energy Conversion. Macromolecules, 2017, 50, 13, 49624971.

(8) Zhong, X.; Chen, H.; Wang, M.; Gan, S.; He, Q.; Chen, W.; He, F. Effect of Halogenation in Isoindigo-Based Polymers on the Phase Separation and Molecular Orientation of Bulk Heterojunction Solar Cells. Macromolecules, 2019, 52, 2393-2401.

(9) Liu, Z.; Gao, Y.; Dong, J.; Yang, M.; Liu, M.; Zhang, Y.; Wen, J.; Ma, H.; Gao, X.; Chen, W.; Shao, M. Chlorinated Wide-Bandgap Donor Polymer Enabling Annealing Free Nonfullerene Solar Cells with the Efficiency of 11.5\%. J. Phys. Chem. Lett., 2018, 9, 6955-6962.

(10) Hu, Z.; Chen, H.; Qu, J.; Zhong, X.; Chao, P.; Xie, M.; Lu, W.; Liu, A.; Tian, L.; Su, Y.A.; Chen, W; He, F. Design and Synthesis of Chlorinated Benzothiadiazole-Based Polymers for Efficient Solar Energy Conversion. ACS Energy Lett., 2017, 2, 753-758.

(11) Ibraikulov, O. A.; Heinrich, B.; Chávez, P.; Bulut, I.; Ngov, C.; Boyron, O.; Brouckaert, N.; Swaraj, S.; Gerasimov, K. L.; Ivanov, D. A.; Mery, S.; Leclerc, N.; Lévêque, P.; Heiser, T. Face-on orientation of fluorinated polymers conveyed by long alkyl chains: a prerequisite for high photovoltaic performances. J. Mater. Chem. A, 2018, 6, 12038-12045. 
(12) Ibraikulov, O. A.; Wang, J.; Kamatham, N.; Heinrich, B.; Méry, S.; Kohlstädt, M.; Würfel, U.; Ferry, S.; Leclerc, N.; Heiser, T.; Lévêque, P. ITO Free Organic Photovoltaic Modules Based on Fluorinated Polymers Deposited from Non-Halogenated Solution: A Major Step Towards Large-Scale Module Production. Solar RRL, 2019, doi.org/10.1002/solr.201900273.

(13) Ibraikulov, O.A.; Bechara, R.; Chávez, P.; Bulut, I.; Tastanbekov, D.; Leclerc, N.; Hébraud, A.; Heinrich, B.; Berson, S.; Lemaitre, N.; Chochos, C.L.; Lévêque P.; Heiser, T. Pyridal[2,1,3]thiadiazole versus benzo[2,1,3]thiadiazole as an acceptor unit in a low-band gap copolymer for photovoltaic applications. Org. Elect., 2015, 23, 171-178.

(14) Zhang, Y.; Chien, S.-C.; Chen, K.-S.; Yip, H.-L.; Sun, Y.; Davies, J. A.; Chen, F.-C.; Jen, A.K.Y. Increased open circuit voltage in fluorinated benzothiadiazole-based alternating conjugated polymers. Chem. Commun., 2011, 47, 11026-11028.

(15) Hu, Z.; Chen, H.; Qu, J.; Zhong, X.; Chao, P.; Xie, M.; Lu, W.; Liu, A.; Tian, L.; Su, Y.A.; Chen, W.; He, F. Design and Synthesis of Chlorinated Benzothiadiazole-Based Polymers for Efficient Solar Energy Conversion. ACS Energy Lett., 2017, 24, 753-758

(16) Wąsik, R.; Wińska, P.; Poznański, J.; Shugar, D. Synthesis and Physico-Chemical Properties in Aqueous Medium of All Possible Isomeric Bromo Analogues of Benzo-1hTriazole, Potential Inhibitors of Protein Kinases. J. Phys. Chem. B, 2012, 116, 7259-7268

(17) Remy, R.; Weiss, E. D.; Nguyen, N. A.; Wei, S.; Campos, L. M.; Kowalewski, T.; Mackay, M. E. Enthalpy of fusion of poly(3-hexylthiophene) by differential scanning calorimetry. J. Pol. Sci B: Pol. Phys., 2014, 52, 1469-1475. 
(18) Li, Z.; Jiang, K.; Yang, G.; Lai, J. Y. L. ; Ma, T.; Zhao, J. ; Ma, W.; Yan, H. Donor polymer design enables efficient non-fullerene organic solar cells. Nat. Commun., 2016, 7, 13094.

(19) Schulz, G.L.; Fischer, F.S.U.; Trefz, D.; Melnyk, A.; Hamidi-Sakr, A.; Brinkmann, M.; Andrienko, D.; Ludwigs, S. The PCPDTBT Family: Correlations between Chemical Structure, Polymorphism, and Device Performance. Macromolecules, 2017, 50, 1402-1414.

(20) Cavallo, G.; Metrangolo,P.; Milani, R.; Pilati, T.; Priimägi, A.; Resnati, R.; Terraneo, G. The Halogen Bond. Chem. Rev. 2016, 116, 2478-2601.

(21) Gilday, L.C.; Robinson, S.W.; Barendt, T.R.; Langton, M.J.; Mullaney, B.R.; Beer, P.D. Halogen Bonding in Supramolecular Chemistry, Chem. Rev. 2015, 115, 7118-7195.

(22) Lia, J.; Hub, Y.H.; Geb, C.W.; Gonga, H.G.; Gao, X.K. The role of halogen bonding in improving OFET performance of a naphthalene diimide derivative. Chinese Chem. Lett. 2018, $29,423-428$

(23) Noh, J.; Jung, S.; Koo, D.G.; Kim, G.; Choi, K. S.; Park, J.; Shin, T.J.; Yang, C.; Park, J. Thienoisoindigo Based Semiconductor Nanowires Assembled with 2-Bromobenzaldehyde via Both Halogen and Chalcogen Bonding, Sci. Reports, 2018, 8:14448.

(24) Kawashima, K.; Fukuhara, T.; Suda, Y.; Suzuki, Y.; Koganezawa, T.; Yoshida, H.;

Ohkita, H.; Osaka, I.; Takimiya, K. Implication of Fluorine Atom on Electronic Properties, Ordering Structures, and Photovoltaic Performance in Naphthobisthiadiazole-Based Semiconducting Polymers. J. Am. Chem. Soc., 2016, 138(32), 10265-10275.

(25) Gao, X.; Shen, J.; Hu, B.; Tu, G. A Straightforward Synthesis of Chlorine-Bearing Donor-Acceptor Alternating Copolymers with Deep Frontier Orbital Levels. Macromol. Chem. Phys., 2014, 215, 1388-1395. 
(26) Yang, Z.; Chen, H.; Wang, H.; Mo, D.; Liu, L.; Chao, P.; Zhu, Y.; Liu, C.; Chen, W. He, F. The integrated adjustment of chlorine substitution and two-dimensional side chain of low band gap polymers in organic solar cells. Polym. Chem., 2018, 9(8) 940-947.

(27) Zhong, Y.; Biniek, L.; Leclerc, N.; Ferry, S.; Brinkmann, M. Segregated versus disordered stacking in two low bandgap alternated copolymers for photovoltaic applications: Impact of polymorphism on optical properties. Macromolecules, 2018, 51, 4238-4249.

(28) Kulkarni, A. P.; Tonzola, C. J.; Babel, A.; Jenekhe, S. A. Electron Transport Materials for Organic Light-Emitting Diodes. Chem. Mater., 2004, 16, 4556-4573.

(29) Huang, J.; Xie, L.; Hong, L.; Wu, L.; Han, Y.; Yan, T.; Zhang, J.; Zhu, L.; Wei, Z.; Ge, Z. Significant influence of halogenation on the energy levels and molecular configurations of polymers in DTBDT-based polymer solar cells. Mater. Chem. Front., 2019, 3, 1244-1252. 
For table of content use only

\section{Benzothiadiazole halogenation impact in conjugated polymers, a comprehensive study}

Théodore Olla, † Olzhas A. Ibraikulov,,+ Stéphanie Ferry, $†$ Olivier Boyron, $\$$ Stéphane Méry, $\nabla$

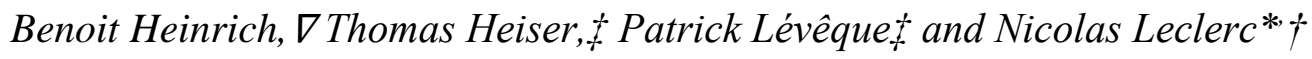
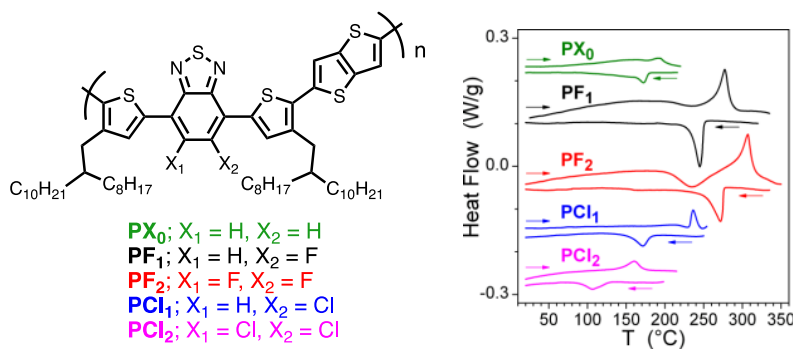